\title{
Review of Experimental-Numerical Methodologies and Challenges for Floating Offshore Wind Turbines
}

\author{
Peng Chen ${ }^{1}$ - Jiahao Chen ${ }^{2}$. Zhiqiang Hu ${ }^{1,3}$
}

Received: 15 July 2019 / Accepted: 1 May 2020 / Published online: 12 October 2020

(C) The Author(s) 2020

\begin{abstract}
Due to the dissimilar scaling issues, the conventional experimental method of FOWTs can hardly be used directly to validate the full-scale global dynamic responses accurately. Therefore, it is of absolute necessity to find a more accurate, economic and efficient approach, which can be utilized to predict the full-scale global dynamic responses of FOWTs. In this paper, a literature review of experimental-numerical methodologies and challenges for FOWTs is made. Several key challenges in the conventional basin experiment issues are discussed, including scaling issues; coupling effects between aero-hydro and structural dynamic responses; blade pitch control strategies; experimental facilities and calibration methods. Several basin experiments, industrial projects and numerical codes are summarized to demonstrate the progress of hybrid experimental methods. Besides, time delay in hardware-in-the-loop challenges is concluded to emphasize their significant role in real-time hybrid approaches. It is of great use to comprehend these methodologies and challenges, which can help some future researchers to make a footstone for proposing a more efficient and functional hybrid basin experimental and numerical method.
\end{abstract}

Keywords Floating offshore wind turbines $\cdot$ Hybrid approach $\cdot$ Basin experiment $\cdot$ Numerical simulation $\cdot$ Wind energy

\section{Introduction}

\subsection{Background}

In the face of rapidly growing energy demands and increasingly harsh environmental conditions, traditional energy supply will hardly meet the demand for sustainable development. Offshore wind has its enormous potential in renewable energy

\section{Article Highlights}

- Several basin experiments, industrial projects and numerical codes are summarized and discussed.

- Integrated new challenges that distinguish them from traditional ones in basin model experiments and those in wind tunnel experiments. - Discussion of the state-of-the-art real-time hybrid approaches.

Peng Chen

p.chen8@ncl.ac.uk

1 School of Engineering, Newcastle University, Newcastle upon Tyne NE1 7RU, UK

2 Guangdong Electric Power Design Institute Co., Ltd. of China Energy Engineering Group, Guangzhou 510663, China

3 College of Shipbuilding Engineering, Harbin Engineering University, Harbin 150001, China markets, worldwide (James and Ros 2015). Compared with conventional fixed-bottom offshore wind, the floating offshore wind turbines (FOWTs) can take the merits of abundant wind resources over the deeper sea, also as the capacity of being dragged out to the wind site and assembly in port (Stewart and Muskulus 2016a). Meanwhile, reduction of visibility impacts if their distance far from the coast (Musial et al., 2003; Sclavounos 2008).

The concept of FOWTs was firstly proposed by Heronemus (1972). Being dependent on the way of supporting the platform to obtain stability and restoring force, three mainly basic concepts were proposed which are (Butterfield et al. 2007): spar-buoy, tension-leg platform (TLP) and semi-submersible. General design details of offshore structures can be found in the literature (Chakrabarti 2005). The economics are also essential to consider when comparing different floaters or improve the original design, not just wave, current and windinduced motions of performance.

Under this demand, different levels of concepts were presented (Table 1), some of them have been realized with the remarkable progress of the wind industry. As a leading role, the world's first floating wind farm, Hywind, has been settled about 15 miles from Peterhead in Aberdeenshire, Scotland, in 
Table 1 Different levels of concepts

\begin{tabular}{lll}
\hline Concepts & Year & Pertinent literature \\
\hline Hywind & 2005-2009 (OC3 IEA Task 23, Subtask 3) & Myhr et al. (2011); Nielsen et al. (2006) \\
WindFloat & 2009 (project start) & Cermelli et al. (2009); Roddier et al. (2009) \\
DeepCwind & 2010-2013 (OC4 IEA Task 30) & Robertson et al. (2013) \\
Sway & $2012(1 / 6.5$ th scale prototype) & Koh et al. (2016) \\
Blue H & 2009 (75\% Prototype) & Ng and Ran (2016) \\
\hline
\end{tabular}

2017 (González and Diaz-Casas 2016). For basin model tests, Tri-Floater (Bulder et al. 2002; Courbois 2013; Huijs et al., 2014; Huijs et al., 2013), HiPRWIND (Ishihara et al. 2009), NauticaWindpower AFT, WindSea (Windsea 2010), Poseidon Floating Power, by the Netherlands' Floating Power Plant AS, Pelastar TLP (Vita et al. 2015), Vertiwind, Nautilus (Fernandez et al. 2013), Iberdrola (Amate et al., 2014) and VolturnUS (Viselli et al. 2015) have been tested in a wave tank in a scale between $1 / 130$ and 1/2 in Europe (Müller et al. 2014).

FOWTs are highly complex systems. The dynamic models of FOWTs, which account for the coupling between aerodynamics loads (turbine) and hydrodynamics loads (floater and mooring lines), flexible structural components (turbine and floater), elasticity, blade pitch controls and restoring effect of the mooring lines, are needed to validate their technical and economic feasibility (Jonkman 2009). In these scenarios, how to predict and validate a new or improved full-scale concept (Butterfield et al. 2007; Liu et al. 2017a, b) under high coupling effects has also been receiving great attention and lead to rapid research progress by both academia and industry, for their sophistication in the design process (Butterfield et al. 2007).

\subsection{Validation of the Technical Feasibility}

Generally, scaled model experiments, numerical analysis and on-site measurements are three reasonable methods to demonstrate the technical feasibility of the FOWTs.

\subsubsection{On-site Measurements}

For on-site measurements, the first truly floating wind turbine system Hywind (Jonkman and National Renewable Energy L 2010) was installed in the Norwegian waters in 2009, achieving a historic breakthrough in operation (Stiesdal 2009). Figure 1 shows the world's first floating wind farm (Hill 2018).

Later, Principle Power installed WindFloat on the Portuguese coast. Aubault et al. (2009), Cermelli et al. (2009) and Roddier et al. (2010) conducted a comprehensive feasibility analysis of WindFloat, the first published design criteria for this concept. Principle Power (2019) provided the $3 \mathrm{D}$ visualization of the prototype, which attaches related component description (Figure 2).

In 2010, one half-scale and one full-scale semi-type FOWTs were demonstrated in Japan (Ishida et al. 2013). The MOE Project (Figure 3) was the first grid-connected FOWT in Japan (100-kW half-scale model) and the fullscale FOWT has also been installed (2 MW). The survivability of the spar type FOWT against typhoon attack has been proven (Arakawa 2015).

However, the published data of these on-site measurements can be used for validating new concepts of FOWTs which is still scarce and limited, due to the exclusive rights of data by various companies and research institutes.

\subsubsection{Numerical Simulation and Model Scale Experiment}

In contrast, the numerical analysis method is time saving and low cost. However, the numerical fidelity of different software is still under testing in terms of innovative optimization methodologies, computational efficiency and accuracy. Despite there are numerous sophisticated numerical tools arising (Jonkman and Buhl Jr 2005), the experiment of a scale model with a controlled environment can still be seen as an essential validation step of the qualification process of system behaviour, non-linear phenomena, extreme and detailed loads and validating codes (Bachynski et al. 2016). For example, extreme wave and viscous loads, or wave-current interaction

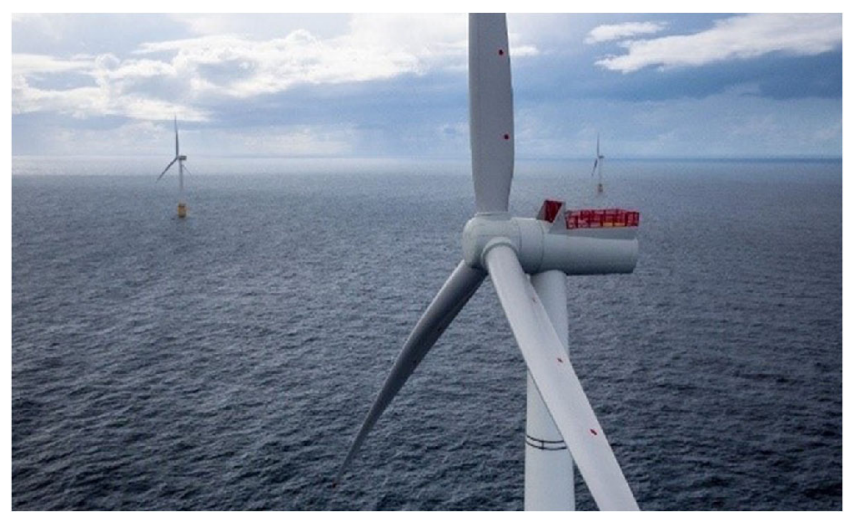

Figure 1 The world's first floating wind farm (Hill, 2018) 


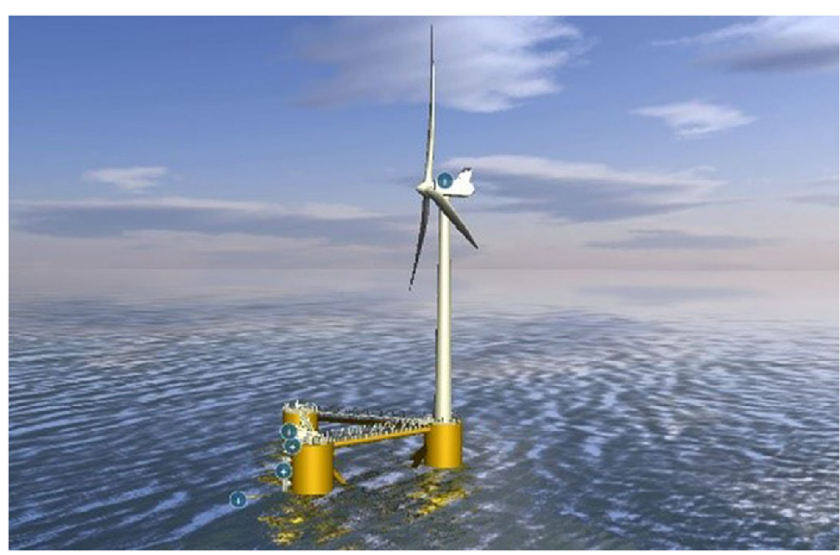

Figure 2 The 3D Windfloat (Principle Power, 2019)

effects on floating moored structures are impossible to be simulated or modelled in numerical simulation in the current state (Sauder et al. 2016). Therefore, experimental

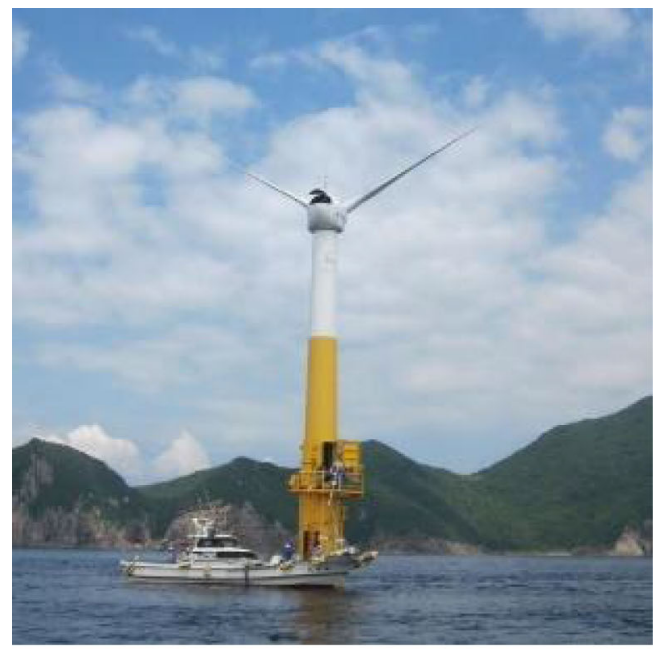

(a) $100 \mathrm{~kW}$ in 2012 (Ishida et al., 2013)

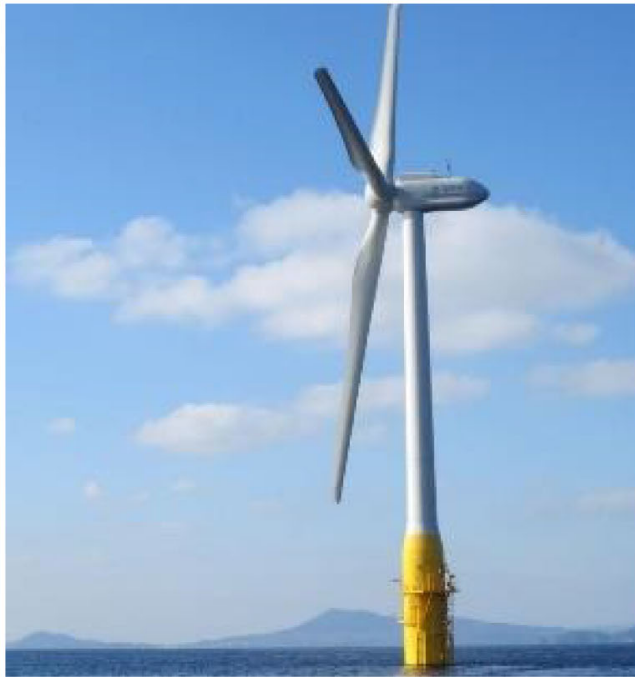

(b) $2 \mathrm{MW}$ in 2013 (Arakawa, 2015)

Figure 3 Two full-scale FOWT projects in Japan assessments in terms of preliminary platform, turbine controller and mooring lines have been regarded as a useful and reliable method to predict global dynamic response of floating structures in the overall design and validation process apart from novel challenges. In addition, time efficiency and risk assessment have been required while demonstrating better controls and repeatable environmental conditions and accurate data than in front of the two (Chen et al. 2018).

Nonetheless, there are critical challenges when conducting a basin experiment of FOWTs. For hydrodynamic similarity of general loads acting on typical offshore structures, the Froude scale method needs to be applied (Chakrabarti 1998; Faltinsen 1993; Sarpkaya and Isaacson 1981). During the early stage of investigations, scholars applied the customary Froude scale method to recreate the dynamics of full-scale FOWTs in basin experiment. However, the dominance of the non-dimensional surrounding medium (aero-hydro) in two different phases which pose general critical challenges in FOWTs' experiments makes scaling without compensation cause discrepancies in the results (Hall and Goupee 2018). In this case, the scaling of the Reynolds number leads to an error inevitable for both hydrodynamics and aerodynamics. As a result, the Reynolds number of a model in the experiment will be much smaller than the full-scale value and significantly changing on aerodynamic performance (rotor) is therefore out of scale. Therefore, it is a great challenge for FOWTs' basin experiments to simulate accurate aerodynamic force and performance under the Froude scale and low Reynold number. Especially, for not advanced and fully equipped facilities, even wind generation techniques over the wave basin may be impractical (Martin et al. 2014). A brief comparison of these three methods is provided in Table 2 .

Several approaches have been proposed by using a tuned drag disk or redesigned rotor and blade to deal with scaling issue (José et al. 2014). Also, several code-to-code approaches have arisen in recent years to counter these challenges (Cordle and Jonkman 2011) and many hybrid basin experimental methods have been proposed, but there is limited academic literature to pertain to provide comparisons and conclusions on these methods in recent years.

Regarding the research of China's FOWTs, in recent years, Chinese scholars have made great efforts and achievements worthy of attention. Chen et al. (2019) systematically studied the dynamic mechanism and the fully coupled time domain simulation program for offshore floating wind turbines; Ma et al. (2015) systematically analysed the dynamic performance of single-column FOWTs through numerical calculations; $\mathrm{Hu}$ et al. (2016) compared the motion of semi-submersible FOWTs under working and downtime conditions; Duan et al. $(2016 \mathrm{a}, \mathrm{b})$ systematically completed a series of model experiments of spar-type and semi-type FOWTs; Li et al. $(2018 \mathrm{a}, \mathrm{b})$ analysed the short-term fatigue characteristics of the tower base under a random wind and wave load. Wan 
Table 2 Comparison of three different methods

\begin{tabular}{lll}
\hline Methods & Advantages & Disadvantages \\
\hline On-site measurement & $\begin{array}{l}\text { More accuracy; } \\
\text { The actual sea state; }\end{array}$ & $\begin{array}{l}\text { Limit published data; } \\
\text { Difficult to measurement; } \\
\text { Expansive cost and high risk; } \\
\text { Time-consuming high resources required; } \\
\end{array}$ \\
& Faster; & High fidelity of numerical model; \\
Cheaper; & Hard to simulate non-linear phenomena; \\
Convenient & Non-linear hydro-aero phenomena; \\
Model scale experiment & Better controls and repeatable environmental conditions; & Scaling issues; \\
& & High specific facilities required; \\
\hline
\end{tabular}

developed the CFD solver NAOE-FOAM-OS-SJTU for marine and marine engineering based on OpenFOAM and overlapping grid technology (Ai and Wan 2017; Cheng and Wan, 2017; Huang et al. 2017). This solver has been used widely to carry out a series of research and analysis on semi-submersible FOWTs, including studying the coupled dynamic characteristics under different blade tip speed ratios, the platform motion under the combined wind and waves, and the impact of towers on the aerodynamic performance of FOWTs. Cao et al. (2013), Tang et al. (2014), Tang et al. (2013) and Li et al. (2017) designed a new type of semi-submersible FOWTs and carried out analysis and research on its hydrodynamic motion performance and overall structural strength. The results demonstrate that the wind turbine system has good performance, and its mooring system has sufficient ability to resist extreme sea conditions, but the two ends of the diagonal support of the tower and the pillar are relatively stressful and critical parts. In addition, Liu et al. (2018) designed a new type of semi-submersible-pillar hybrid FOWTs and used SESAM and FAST software to perform time domain calculations. That research also extended to the calculation method of a fixed vertical axis wind turbine to floating type and compiled corresponding calculation programs (Li et al. 2017). Zhang et al. (2013) studied the dynamic response under turbulent wind. Subsequently, they also independently designed a threebuoy floating platform foundation for the 5-MW wind turbine and carried out design research on its hydrodynamic performance such as stability, wave resistance and anchor positioning (Zhang and Deng 2011). In addition, Zhao et al. (2012) also designed and calculated a 3-MW offshore floating vertical axis wind turbine. Lu et al. (2016b) used FAST-Orcaflex software to conduct a series of analyses on FOWT mooring systems, and proposed a set of mooring systems design methods (Lu et al. 2016a, b; Lu et al. 2018). Lu et al. (2017) also made a frequency domain response analysis of the aerodynamic damping performance and designed the concept of reinforced concrete FOWTs. Jin and Teng (2016) developed a time domain coupled numerical program for FOWTs, which has been utilized to calculate the OC3-Hyiwnd. Shi (2015) performed an analysis of the overall motion characteristics and structural dynamic response of the single-column extension tension leg FOWTs, and optimized the structural size based on its fatigue characteristics.

\subsection{Theoretical Analysis and Experiment of FOWTs}

The theoretical analysis results need to be compared with the basin model test and on-site measurement to determine the availability and accuracy, and promote the development of the theory. Conversely, theoretical guidance can improve the methodology of the experiment and numerical simulation. In short, the three methods are of great importance, which are required for different research stages.

In the preliminary design stage of FOWTs, the theoretical analysis and the calculation can be used to quickly complete the selection work. In the stage of fine design, numerical calculation and wind tunnel or basin model test are the main research methods. After the physical design, the experiment becomes the main force.

This review article aims to critically compare and conclude these state-of-the-art approaches in terms of the horizontal axis floating offshore wind turbines to help future researchers to make a footstone for proposing a more efficient and functional hybrid basin experimental method.

\section{Progress of Model Tests on FOWTs}

It is well acknowledged that basin experiment for FOWTs can predict non-linear aero-hydro phenomena and also better controls and repeatable environmental conditions. In this chapter, several basin experiments and typical industrial projects are discussed in terms of validation and progress.

In an earlier stage, the significant R\&D effort of FOWTs has been made with the appearance of coupled hydro-aero tools (Jonkman et al., 2009; Jonkman and Sclavounos 2006; Wayman et al. 2006). Several concepts for FOWTs have been proposed in Japan in the early stage (Fukumoto et al. 2006; Iijima et al. 2013; Ishihara et al. 2007; Ishihara et al. 2006; Ishihara et al. 2009; Kitamura et al. 2006; Ohkawa et al. 2004; 
Sukegawa et al. 2006; Van Phuc and Ishihara 2007; Yago et al. 2007). And a national demonstration project of FOWTs was conducted by the Ministry of the Environment of Japan in 2010. A half-sized floater with a 100-kW wind turbine and a full-sized floater with a 2-MW turbine were monitored in the same position and the measured record including huge typhoon condition is also presented, respectively (Arakawa 2015).

The safety and performance of their type of concept were investigated by Utsunomiya et al. (2013a) based on one a 1/ 100 scale model (Utsunomiya et al. 2009a) and a 1/22.5 scale model (Utsunomiya et al. 2009b). In a 1/10th scale model (Utsunomiya et al. 2013b), the static catenary line theory and modified Morison's equation are used in time domain code analysis which shows discrepancies in drag force without damping of mooring lines will induce significant motion responses. In a 1/22.5 campaign, Utsunomiya et al. (2009b) examined the model under the regular and irregular wave and combing a steady horizontal force corresponding to a steady wind to replicate a steady thrust force from the blade in the aerodynamic part.

This experiment focused only on the wave loading and generating of steady force in open basin space instead of wind. But there was lost of sight of the coupling effect between wind and wave, especially blade rotating and scaling issues in aerodynamic load simulation. And the validation for half size was in parked condition at NMRI (Kokubun et al. 2012). Experimental descriptions aiming at a full scale have been given by their paper (Utsunomiya et al. 2014), which introduced one dynamic analysis tool including MSC Adams (Jonkman and Buhl Jr 2005), NREL/AeroDyn (Laino and Hansen 2002), SparDyn (in-house) and Moorsys (in-house). His tests cover dynamic analysis and simulation validation of simplified scale model tests under extreme condition. Utsunomiya et al. (2013a, b) also compared the numerical calculations. In summary, full-scale tests have been conducted at the ocean (Ishida et al., 2013; Utsunomiya et al. 2013a, b) and the derivation of their numerical model was provided by Matsukuma and Utsunomiya (2008).

In 2012, Sethuraman and Venugopal (2013) performed a model experiment in a curved wave tank in the University of Edinburgh. Their model was fundamentally comparable with the work of Utsunomiya et al. (2013a, b). The surge motions have a significant reduction by comparing the mooring line and four-point mooring configuration which was compared with the former's work. The OrcaFlex software has been applied to the numerical modelling analysis. Later, Chujo et al. (2013) conducted a basin test, based on the Fukushima project (Forward 2014) with various phases including model and prototype tests as well as the blade pitch control. Continue to part of the work of Duan et al. (2016a, b), several studies on FOWTs are summarized in Tables 3 and 4. In the next part of this chapter, a few projects will be briefly introduced.

\subsection{OC Projects}

As the leading projects, the phase IV of OC3 (Jonkman and Musial 2010), phase II of OC4 (Robertson and National Renewable Energy L 2014) and OC5 Project phase II (Robertson et al. 2017) operated under IEA Wind Tasks for the NREL are the most illustrative projects (Table 5).

\subsubsection{Hywind}

The Hywind was the first large-capacity FOWTs which has been installed $10 \mathrm{~km}$ away from the southwest coastline of Norway in 2009 by Statoil, achieving a historic breakthrough in the operation of FOWTs (Stiesdal 2009). It adopted a single-column floating body as a support structure with a rated power of 2.3 MW. The water depth is $200 \mathrm{~m}$ and is moored by the anchor chain connected by 3 sets of delta connection. Statoil has done a lot of actual measurements on their response and operation under wind and wave loads.

As early as 2006, Nielsen et al. (2006) and Skaare et al. (2007) performed model tests for a 5-MW Spar-hull for Hydro Oil \& Energy at MARINTEK based on a 1/47 scale where Froude scaling was applied. Couple wave and wind load cases were conducted and the control strategy consistent with the actual FOWTs was applied in testing when the wind speed is less or higher than the rated wind speed. They conducted code-to-experiment validation by comparing SIMO/RIFLEX and HywindSim and the integration of SIMO/RIFLEX/ HAWC2. And also a new blade pitch control strategy with an active damping algorithm has been used because the loads will amplify or damp the motions of FOWTs if conventional control strategies were adopted (Knauer et al. 2006).

In 2011, Shin (2011) conducted a 1/128 scale model test in 2D and 3D wave tanks and the physical model was built on the Froude number at the Ocean Engineering Wide Tank at the University of Ulsan. The simulation used model blade replicate, the thrust disks of the Hywind, and set a rotating and fixed rotor under regular and irregular wave cases which provided a reference for researchers who later conducted experiments and simulation of Hywind. The FAST (Fatigue, Aerodynamics, Structures, and Turbulence) code and MOSES code also were utilized for validation. Myhr et al. (2011) conducted one 1/100 scaled model test which compared Tension-Leg-Buoy (TLB) and Hywind by experiment and code analysis (3D float and ANSYS). The smaller motions have been found in experiments and computations may be resulted in calibration.

Duan et al. (2016a, b) examined two different blade systems based on a 1/50 scale spar type: the thrust matched (TMBS) and the geometry matched (GMBS) under different environmental conditions at Deepwater Offshore Basin of SJTU. Two different blades have been discussed in more details by Chen et al. (2018) and an improved deficient thrust 
Table 3 Summary of several studies

\begin{tabular}{lllll}
\hline Author/org & Year & Classification & Model type & Scale ratio \\
\hline José et al. (2014) & 2014 & Hybrid model test & Concrete Star Wind Floater & $1: 40$ \\
Bayati et al. (2018a) & 2014 & Hybrid model test & - & $1: 25$ \\
Sauder et al. (2016) & 2016 & Real-time hybrid model test & Braceless semi-type & $1: 30$ \\
Hall and Goupee (2018) & 2018 & Real-time hybrid model test & DeepCwind semi-type & $1: 50$ \\
\hline
\end{tabular}

force correction approach has been proposed by Li et al. (2018a, b).

\subsubsection{DeepCwind}

In $2011,1 / 50$ scale model tests on three types floater of FOWTs have been performed by Goupee et al. (2012) by using a geometrically scaled reference turbine (NREL $5 \mathrm{MW}$ ). They changed the wind speed from $11.4 \mathrm{~m} / \mathrm{s}$ (rated speed) to $21.8 \mathrm{~m} / \mathrm{s}$ to offset of the turbine force. It allows the thrust to match the desired value for the low performance of the original geometric scale wind turbine model. Martin (2011) outlined the details of the test and procedure. The examination of the test data is provided by Robertson et al. (2013), which also shows a very thorough insight available on the practical capability of FAST (Jain et al. 2012) and experimental investigation of the three major FOWTs.

Goupee et al. (2014b) demonstrated the unique advantages and disadvantages of three concepts which are TLP, Spar and Semi. The study proposed a new model blade with better $C_{t}$ and $C_{p}$ aerodynamic performance at the Froude scale model wind speed, and the control strategy was applied in this experiment. The test matrix of the global performance of three FOWTs and system identification were concluded by Koo et al. (2014) in terms of hammering test, free decay test and white noise test. In 2011, as part of the DeepCwind, Gueydon and $\mathrm{Xu}$ (2011) conducted a 1/50 geometrically identical to Hywind test with a full-scale modified mooring system in a water depth of $200 \mathrm{~m}$. The multi-body time domain simulation program aNySIM created by MARIN was utilized to calibrate by matching during the decay test. However, the horizontal drift motions could not be simulated in software, because of the error of notable differences in motion response statistics.

In 2013, de Ridder et al. (2013) conducted the same Semi model which has been conducted under improved testing conditions in the MARIN. This experiment was designed with a comparison to the previous campaign. Besides, another 1/130 scale model has been used to assess the reliability which can be noted by Kimball et al. (2014). The proper scaling methodology is as follows: Adopting a redesigned 125\% NREL 5MW reference turbine (Fowler et al. 2013; Martin et al. 2014) to satisfy the performance-matched turbine (MSWT) which can be seen as a significant Landmark exploration. Masciola et al. (2013) compared the numerical results of interacted mooring dynamics with MARIN test data for a 1/50 scale Froude model subjected to equivalent sea states. And a fullscale model has been calibrated and validated within FAST (Stewart et al. 2012).

\subsection{INNWIND.EU}

A 1/60 scale OC4 DeepCWind semi-submersible model was used to perform a recent test led by INNWIND.EU project (Sandner et al., 2015). A Froude-scaled rotor was designed with the characteristics of:

- Constant rpm;

- Feedback controlled ducted fan;

- Real-time hardware-in-the-loop (HIL) controlled;

- No wind generator.

Although the Reynolds numbers between the models and full scale do not match, they are still necessary for experiments with high-chord blades to match the rotor thrust. And also, a

Table 4 Contributions

\begin{tabular}{ll}
\hline Author/org & Contributions \\
\hline $\begin{array}{l}\text { José et al. (2014) } \\
\text { Bayati et al. } \\
(2018 \mathrm{a}, \mathrm{b})\end{array}$ & $\begin{array}{c}\text { Using a ducted fan mounted at the tower top to provide the required thrust force. } \\
\text { Test in the wind tunnel and simplified the 6DOF motions by the actuator }\end{array}$ \\
$\begin{array}{c}\text { Sauder et al. } \\
\text { (2016) }\end{array}$ & $\begin{array}{c}\text { Using actuators to provide the transient simulated force rather than a ducted. Considered } \\
\text { effects between the wind forcing, wave forcing and the blade pitch control algorithm }\end{array}$ \\
$\begin{array}{c}\text { Hall and Goupee } \\
(2018)\end{array}$ & $\begin{array}{c}\text { Using the actuation system combined numerical wind turbine model was set to simulate } \\
\text { thrust force by winch and cables, pulling fore and aft on the nacelle. }\end{array}$ \\
\hline
\end{tabular}


Table 5 OC Projects

\begin{tabular}{llll}
\hline Author/org & Abbr. & Year & Content \\
\hline IEA Wind Annex 30 & OC3 & $2005-2009$ & Phase IV: Hywind \\
IEA Wind Annex 30 & OC4 & $2010-2013$ & Phase II: DeepCwind \\
NREL and Fraunhofer IWES & OC5 & $2014-2018$ & Phase II: DeepCwind \\
NREL & OC6 & 2019-2022 & - \\
\hline
\end{tabular}

research of the 1/60 Froude-scaled DTU 10-MW (Bak et al., 2013) TLP is detailed in Bredmose et al. (2015) and Laugesen and Hansen (2015). It also has been presented by PegalajarJurado et al. (2016) as a part of INNWIND.EU. The numerical model (Ramachandran 2013) is implemented in Flex5 (Øye, 1996) on the scale of $1 / 60$ as well.

\subsection{LIFES50+}

In the LIFES50+ project, some innovative new substructure concepts have been proposed which focus on water depths from $50-200 \mathrm{~m}$ and the 10-MW FOWT. There is an interesting campaign testing the performance of FOWTs but not in basin tank. Bayati et al. (2013) performed a 2-DoF (pitch and surge motion) experimental rig-HexaFloat at Politecnico di Milano Wind Tunnel to simulate a $1 / 25$ scale DTU 10 -MW wind turbine model. This combined hydrodynamic and aerodynamic loads within the LIFES50+ project (Bayati et al. 2016). Next year, HexaFloat has been expanded to 6DOFs (Bayati et al. 2014). In 2017, they proposed an aerodynamic design methodology and a scaled model technology for a $1 /$ 75 scale DTU 10-MW wind turbine rotors (Bayati et al. 2017a).

\subsection{WindFloat}

In October 2011, Principle Power installed a semi-type WindFloat in Portugal, with a rated power of $2 \mathrm{MW}$ and a working water depth of $45 \mathrm{~m}$. The foundational predecessor of WindFloat is MiniFloat. Fulton et al. (2006) and Zambrano et al. (2006) proposed this Semitype floater MiniFloat (Roddier et al. 2009). Cermelli et al. (2010) conducted a $1 / 67$ th scale-scale model testing campaign in 2010 at the University of California Berkeley Ship Model Testing Facility in the first phase of the WindFloat platform which is based on the hydrodynamic and structural studies of MiniFloat (Aubault et al. 2007; Aubault et al. 2006; Cermelli and Roddier 2005; Cermelli et al. 2008; Cermelli et al. 2004). One disk with a diameter of $27 \mathrm{~m}$ was used to provide the same thrust force (using Froude scaling) to simply the issues of different Reynolds and turbine control (Larsen and Hanson, 2007). After the experiment, extensive finite-element analyses and the FAST code were carried out. In the same year, Roddier et al. (2010) performed a 1/105 small-scale model test which combined with the numerical analysis tools including TIMEFLOAT and FAST. In this experiment, one electrical motor was placed to model the gyroscopic effect and the disk still was utilized to replace the wind turbine under the selected drag coefficient 1.2 , wind speed $12 \mathrm{~m} / \mathrm{s}$ and 0.4 after that up to $25 \mathrm{~m} / \mathrm{s}$, respectively.

\subsection{Winflo and AFOSP}

To predict the global dynamic responses of an innovative concept, Le Boulluec et al. (2013) conducted scaled model tests and included an adapted rotor to validate the floater and mooring within the Winflo project in 2010 (Henderson and Witcher 2010). And experimental results show the moored floater has a superior ability to hand the hydro/aero coupling and gyroscopic effects induced by FOWTs.

Within the European KIC AFOSP project, a monolithic concrete spar was developed and the experiment was presented by Molins et al. (2011) and Molins i Borrell et al. (2014). The exemplary design and methodology of the experiment of this novel spar have been demonstrated by Matha et al. (2015) who provide a brief review of the AFOSP project.

\subsection{Floating Wind Offshore Structures}

Philippe et al. (2013) performed a model test of the Dutch Trifloater based on Froude similarity (Courbois, 2013) in ECN. The wind generation system in his experiment can be found in the paper of Courbois et al. (2011a, b). The numerical model (Philippe et al. 2014) they used in the experiment showed a good agreement for three degrees of motions. José et al. (2014) validated a 1/40 scale 6-MW Concrete Star Wind Floater designed by Dr.techn.Olav Olsen AS (Lunde 2013), which used a concrete model in the ECN wave tank in 2014. A new methodology was proposed for the scaling of aerodynamic force by combining the Ducted Fan and hardware iteration to obtain the correct thrust force at the low Reynolds regime. 


\section{Challenges in Basin Experiment Technologies}

Due to the blade rotation and the elasticity of the tower and structure, the FOWTs' experimental model has become complicated. Compared with the traditional floating structure model test, there are numerous key challenges.

Several intrinsic challenges are summarized here, which will affect the accuracy of the wave-wind coupling effects in the basin experiment, as well as making the FOWT basin experiments different from traditional offshore engineering experiments and wind tunnel testing. These challenges include:

\section{Scaling issues:}

Froude number and Reynolds number cannot be satisfied simultaneously; aerodynamic performance simulation; reflecting of coupling effects between aero-hydro and structural dynamic responses.

\section{Blade pitch control strategies:}

Increase of the loads, negative thrust sensitivity and resonant amplification of platform pitch motion.

\section{Experimental facilities and calibration methods:}

Mass property adjustment, installation of measurement devices and wind-wave generator techniques.

\subsection{Scaling Issues}

The first challenge has been regarded as the crucial one which extends the problems of blade design and control strategies caused by dissimilar low Reynolds scaling issue. This involves the consideration of the dynamic similarity criterion.

Generally, the exact simulation of hydrodynamic and aerodynamic forces depends on the similarity of Froude numbers and Reynolds numbers, respectively. And scaling incompatibility is induced by these two factors. The appropriate scale rule and eliminating scale effect as much as possible can be regarded as a very important point to obtain a reasonable overall dynamic response of the whole system.

In response to these existing challenges, early scholars have summarized the existing experiments. Müller et al. (2014) listed some representative basin experiments and projects in the past and put forward a methodology for the existing problems by redesigned model scale rotor. However, aerodynamic torque and gyroscopic momentum are not scaled correctly with his software-in-theloop procedure. Alternatively, rotating scaled mass was used to represent the rotor inertia to match the gyroscopic effects. Stewart and Muskulus $(2016 \mathrm{a}, \mathrm{b})$ reviewed 9 experiments of FOWTs in details, as a preliminary preparation for the Integrated Research Program on Wind Energy (IRPWind).

\subsubsection{Hydrodynamic Simulation}

For the basin model experiment of the traditional floating structure, the Froude scale is usually the priority because the gravitational forces are the main factor to impact hydrodynamics of floater rather than viscous forces (Brown, 2006). And the gravitational and inertial forces in the wave force components can be accurately simulated, which are the dominant external loads for ships or floating offshore structures.

A steady thrust force has been replicated by using a steady horizontal force corresponding to a steady wind from Utsunomiya et al. (2009a, b). Myhr et al. (2011) performed a 1/100 scale TLP platform in 2011. As further work in 2014, they exploited another $1 / 40$ scale TLP and tested at IFREMER to validate the hydro-elastic of three different Tension-LegBuoy (TLB) floaters, compared with an aero-servo-hydroelastic simulation tool (3DFloat). In 2012, a simplified 1/80 scaled TLP model testing has been performed by Wehmeyer et al. (2013) under the ultimate limit state (ULS), therefore no aerodynamic loading and gyroscopic effects. Sethuraman and Venugopal (2013) conducted a 1/100 scaled stepped-spar basin experiment at the University of Edinburgh. Their model was fundamentally comparable with the one of Utsunomiya et al. (2013a, b). Bayati et al. (2015) presented a method to study hydrodynamic loads on the OC4 Semi-type platform with the effects of water depth which has been inspired by previous studies (Naciri et al. 2004; van Essen et al. 2013). Based on the data of previous basin model tests, Gueydon (2016) carried out the validation (without control). Two numerical models were established to examine the design concept and the small-scale constructed physical model which were matched at operating speed, wave and steady wind at a fixed speed.

However, these experiments were focused only on hydrodynamic parts and did not consider the coupling effect induced by another aerodynamic performance including the rotor, blade or other actuators in the experiment. Therefore, the coupling effects between aero-hydro cannot be presented well, especially controller induced platform unstable phenomena.

\subsubsection{Aerodynamic Simulation}

The Reynolds number is usually adopted in wind tunnel tests to validate the size and parameters of the blade and rotor (Jamieson 2018), and to ensure that the viscous forces and inertial forces in the correct airflow field can be obtained. However, the Reynolds number will become much smaller in the basin experiment of FOWTs under the Froude scale, for example, the Reynolds number will reduce to $1 / 350$ under a 1/50th Froude scale (Hall et al. 2014). Therefore, the Reynolds number cannot be considered simultaneously with the Froude number in FOWTs' experiment which means a 
difficulty in replicating the coupling between aero-hydro dynamic forces (Bayati et al. 2017a, b).

If the similarity of the Reynolds number cannot be simulated inappropriately, there will be a significant impact on the aerodynamic performance such as blade performance (lift and drag forces) and aerodynamic damping, resulting in dissimilar thrust force, thus affecting the dynamic response performance of the entire system. Currently, the Froude number is still adopted in the experiment of FOWTs to simulate the correct wave force and inertial force effect which are also the premise rather than the Reynolds number. For this composite model test, the density and dynamic viscosity of the airflow field are unlikely to simulate. Despite having some aerodynamicrelated properties that are affected by the Reynolds number, it mainly reflects the relative relationship between the viscous force and the inertia force (Martin 2011). As a result, the viscid effect usually is neglected in the model test to equate the Froude similarity between the model and full scale to satisfy the gravitational and the inertial similarity.

Nonetheless, the most critical and significant aerodynamic loads are selected out, namely, gyroscopic momentum, thrust force and torque. These three loads are transmitted from the blade to the floater which can represent the main aerodynamic performance (Martin et al. 2014). Gyroscopic momentum can be obtained through satisfying the weight, center of gravity of the blade and rotating speed under the Froude scale. Gyroscopic effect (Gyro-effect) has been studied by many scholars (Bahramiasl et al. 2018; Fujiwara et al. 2011; Murai and Nishimura 2010; Suzuki et al. 2004). The Gyro-effect of rotating blades that induced yaw motion has been proved that will not reduce generator power sharply (Suzuki et al. 2004). Upon the idea of Suzuki et al. (2004), one 1/158 scale model test was conducted by Murai and Nishimura (2010), which adopted an automatic revolving disk rather than blades. And an examined experiment and numerical simulation of Gyroeffect on coupled dynamic responses have been done by Fujiwara et al. (2011), as well as derivation of formulas of gyroscopic damping and motions. In addition, 6 DOFs' equations in the frequency domain have been provided in terms of aerodynamic loads (Semi) (Blusseau and Patel 2012), model test and numerical simulation (TLP) (Bahramiasl et al. 2018). Karimirad (2011) demonstrated the instability of FOWTs, due to high amplitude in yaw and pitch motion coupled by the Gyro-effect.

If the thrust and torque are not corrected, it cannot meet the requirements for correctly simulating the corresponding relationship of the full scale. In addition, it is necessary to determine the priority relationship between thrust force and torque if they cannot be satisfied simultaneously. The thrust force is directly transmitted to the tower and platform which have a significant impact on the whole system. Therefore, providing correctly scaled thrust force is easier and feasible to do since torque is less important for global dynamic responses (Martin et al. 2014) in the case where the rotation axis of the blade is driven by the motor instead of wind.

The platform will undergo 6DOF motions under the action of wind and waves. The aerodynamic load of the wind turbine aggravates the motion responses of the platform. At the same time, the movement of the platform is induced by the speed of the rotor to change the flow field. With unsteady distribution, the aerodynamic load of the rotor changes accordingly. As the rotor rotates continuously, its aerodynamic loads generally change with the rotational position, and the platform motion affects this periodically varying load. Therefore, the platform motion and the rotor load are mutually coupled processes.

This coupling problem poses a challenge for the design and analysis of FOWTs and has received much attention in recent years. Based on the free wake vortex method (FVM), Sebastian and Lackner (2012) analysed the interaction between the rotor and the downwind vortex under the pitch motion of the platform. It is considered that the change of the aerodynamic load caused by the platform pitching motion is not negligible. Sebastian and Lackner (2013) also considered that the platform motions caused an unsteady flow field, compared the aerodynamic loads of fixed and studied the freedom of motions of the platform with different influences on aerodynamics under different platform forms. Jeon et al. (2014) also analysed the effects of pitch motion using the vortex lattice method (VLM). Farrugia et al. (2014) carried out experimental research on the aerodynamic performance of the floating platform, measured the load and wake state of the rotor, and proposed that the FOWTs should reduce the longitudinal motion to avoid running at a relatively high tip speed. Rockel et al. (2014) studied the influence of the platform's pitch motion on the wake through wind tunnel tests. The movement of other degrees of freedom of the floating body may also make the wake more complicated.

Sant and Cuschieri (2015) analysed the rotor properties of the platform at different heading angles according to various models. Wu et al. (2015) used the CFD method to study the effects of platforms' sway, pitch and yaw motions on the aerodynamic loads of the whole rotor and single blade, combined with the velocity distribution of the disk surface and wake. Power and load changes are brought by the platform motion. The analysis was carried out and these changes will be considered as important challenges in the study of control systems, structural fatigue and strength. However, these studies are only for the part of the degree of freedom of the platform motions, lack of comprehensive analysis and comparison of the $6 \mathrm{DOF}$.

\subsection{Rotor Simulation and Blade Pitch Control}

The dissimilarity of direct geometric scale blades cannot match the aerodynamic performance as expected. To avoid the discussed dissimilar problem, several researchers have 
proposed a more sophisticated "non-geometrical" scaling approaches. The new Froude scale rotor and blade have been redesigned to make up to performance reductions of the aerodynamic load modelling in the experiment, including drag disk by Wan et al. (2015) and Cermelli et al. (2010) or a modified low-Reynolds number airfoils with enlarged chord lengths (Duan et al. 2016a, b) to only match the full-scale thrust force (de Ridder et al. 2014; de Ridder et al. 2013; Fowler et al. 2013; Make, 2014).

\subsubsection{Drag Disk}

Principle Power conducted a $1 / 67$ scale model test in the first phase of WindFloat (Cermelli et al. 2010; Cermelli et al. 2009). Taking excessive complexity of simulation control execution into account, a compromise approach was adopted, even disk instead of blades to get enough thrust. In 2010, the Reynolds number has been considered to be well overcome by using enlarged blades in terms of special airfoils and roughened leading edge (Martin 2011). The NREL 5-MW blade was the prototype of that Froude scale rotor. They increased a higher wind speed to match the thrust force to keep the balance in the relationship of aero-hydro dynamic force between the model and full scale. And then in 2013, a second-round testing was conducted based on a semitype platform and the hybrid combination of potential flow theory and Morison's equation has been considered in this specific experiment. The detailed parameters, the definition of external wave conditions and specification of installation (sensors) have been provided in their papers; however, limited experimental results have been published. Although MARIN tested FOWTs equipped with such blades in basin model tests, it was only applied to a semi-submersible platform until this project ended.

Based on phase IV of OC3, Shin (2011) used model blades in replicating the thrust disks to conduct a 1/128 scale model test under stochastic wind and wave. And motions of the platform and rotating rotor effect include linear hydrostatics, excitation force (incident waves), radiation (outgoing) and nonlinear effects (added mass effects and viscous forces) that have been discussed in their research. In addition, the spar torus combination (STC) proposed at NTNU (Wan et al. 2015; Wan et al. 2016a, b; Wan et al. 2017) and semi-wind energy and flap-type wave energy converter (SFC) (Gao et al. 2016; Luan et al. 2014; Michailides et al. 2016; Michailides et al. 2014) have been studied by model tests and numerical validation based on EU FP7 MARINA Platform project. They adopted a drag disk on the top of the tower to replicate the mean thrust on the rotor because it is mainly to validate the structural integrity of STC under severe sea states.

\subsubsection{Re-design Rotor and Blade}

In 2014, three scale relationships including prototype to model (Chakrabarti 1998), Froude-scaled wind and tip speed ratio (TSR) (Jonkman and National Renewable Energy L 2010) have been mentioned by Martin et al. (2014). Hansen et al. (2014) concluded a 1/200 scale TLP with an optimized rotor and low Reynolds number through an alternative pitch angle distribution. Duan et al. (2016a, b) conducted 1/50 scale spartype model tests by comparing the testing results of the TMBS and GMBS under different environmental conditions. Du et al. (2016) examined a similar geometrical blades' aerofoils which show only $24.3 \%$ of the target. He optimized the thrust force of the model and the lift and drag coefficient was obtained by the RANS method. The improved blade referenced by Fowler et al. (2013) has better aerodynamic performance than the original geometrically similar blade and is more in line with the target value, which largely compensates for the inability of the geometrically similar blade to accurately simulate the rotor's performance. And a quasistatic and unsteady methodology has been proposed by Salehyar and Zhu (2015) to analyse the aerodynamic dissipation effect. Although MARIN and SJTU based on geometrically reduced model blades have taken relevant remedial measures at low Reynolds number, its structure for non-rotor parts (such as towers) and parts of the float above the water surface will also produce unwanted extra thrust. To ensure the correct simulation of the axial thrust, the accurate collection of other aerodynamic loads, such as torque, was abandoned.

Ahn and Shin (2017) conducted a 1/128 scale 3-leg catenary spread mooring system with a delta connection. The water depth of the entire system is matched numerically and experimentally in various combinations including wind and rotor rotation to predict platform performance. By comparing the significant motion and RAOs with conventional and irregular waves, the validity of the numerical simulation they proposed can be assured. Due to the small size, the blade must be re-corrected for the thrust force and surge excursion, because the flapwise surface of the 3D blade model was the only one matched in their project. For this reason, 3D printing can be used as another optimal solution for the construction of a small-scale experimental physical model.

In general, the geometric downsizing of the rotor effectively alters the aerodynamics of the scaling issues (Jain et al. 2012). And also, in this method, gyroscopic forces can be provided by a correct mean thrust force and aerodynamic damping, if spinning. However, whether it is a drag disk or a modified blade, the thrust force is the only condition which has been considered in the previous experiment. More detailed investigations' fidelity will lose if the torque, rotor blades' load, scalability for aerodynamic damping at different wind speed and advanced blade pitch control cannot be considered. 


\subsubsection{Blade Pitch Control Strategies}

How to simulate the rotation of the rotor is related to control technology. Adjusting the blade pitch angle and generator torque is one of the most significant requirements in most wind turbines (Pao and Johnson 2011), which are discussed above briefly. In general, under different wind speed region, the control strategies vary.

Wind speed < rated: The maximum power is the priority and the generator torque will adjust (pitch angle keeps 0 ).

Wind speed > rated: The generator torque constant by adjusting pitch angle to maintain stable power output.

It is appropriate for both land-based and floating types. However, due to the particularity of FOWTs, the standard land-based control strategies cannot apply on the floating turbine blade directly (Jonkman 2008). It is a challenge to apply the controller on a floating platform which will lead the floater unstable especially when the damping and the controller mode are within the same bandwidth (Savenije and Peeringa 2014). This is exactly what was mentioned above, the poly-trope of thrust force on the rotor. In this case, good control strategies for active turbine blades and generator control ensure stable operation of FOWTs including maintaining appropriate rotating speed and power regulation (Pardalos et al. 2013), as well as reducing the motions and a substantial load of floater (Savenije and Peeringa 2014). In general, not only the motions of the floater have impacted the superstructure but also controllers will influence the floaters which are also the coupled effects.

Many scholars did numerous researches in these specific blade pitch control strategies (Bakka and Karimi 2012; Christiansen et al. 2013; Lackner Matthew 2013; Larsen and Hanson 2007; Lindeberg et al. 2012; Namik and Stol, 2010, 2011, 2013; Oh et al. 2015; Ramos 2012; Schlipf et al. 2013; Wang et al. 2014). Namik and Stol (2013) provide a detailed review of FOWTs' controllers and introduce an IBP controller. Savenije and Peeringa (2014) provided a brief review of control development for FOWTs and compared four different controllers including FPfloat (fixed pitch), OC3float, ECNland (without modifications) and ECNfloat. Some researchers investigated the active blade pitch control and generator control based on global dynamic responses of FOWTs (Bredmose et al. 2017; Goupee et al. 2017; Yu et al. 2017). Hara et al. (2017) proposed a system identification approach. Their approach adopted an $H^{\infty}$ method (Zhou and Doyle 1998) which was applied by Tsujimoto et al. (2014). Although some blade pitch control systems have been investigated in this area and achieved certain results, there are still few references available in the field of how the control strategies are combined with a real-time hybrid experiment, especially the influence of active turbine controls.

José et al. (2014) proposed another approach that performed a 1/40 scale test of a semi-type FOWTs.
They applied a ducted fan to provide the required thrust force. Although it was controlled via a real-time numerical simulation with active controls, it still had a limited ramping rate and good results integrated with simulation results very well. Goupee et al. (2014a, b) compared two campaigns using a geometrically similar and improved performance-matched DeepCwind model (OC4 Phase II), which have been conducted in 2011 and 2013, respectively. As a corrective measure, the wind speed has been increased to obtain the correct mean thrust force in the 2011 campaign and the coupled aero-hydro-elastic response in region three and active blade pitch control has been tested in 2013 which were not executed in 2011.

Yu et al. (2017) conducted a 1/60 scale Triple Spar floater, a hybrid between a spar-buoy and semi-submersible tri-floater which was tested with an active blade pitch control in DHI Denmark for the first time (Bredmose et al. 2017; Yu et al., 2017). The aerodynamic damping, interaction effects induced by wind, and wave and blade pitch control are discussed in their work. They applied a real-time active controller on the model (Yu et al. 2017). In this campaign, different methodologies of the controller related to negative aerodynamic damping and simulation have been investigated to show the possibility of a low Reynolds rotor to control the rotor speed by adjusted the blade pitch angle. The calibration of the simulation model has also been proposed, due to the lift and drag coefficients and aerodynamic losses and drivetrain mechanical friction.

\subsubsection{Summary}

The model size of the blade is large, and the scaled mass is very light, at the same time it needs to bear various wind loads in the test to meet sufficient strength and rigidity, which involves the blade manufacturing technology.

The upper structure of the FOWTs is very lightweight and at the same time the most complicated part of the arrangement and installation. Especially, it needs to install the motor, connect the hub, the six-component force sensor, the accelerometer sensor and the various components.

Meeting the objective scale quality is a challenging task that involves not only control strategies but also mass control techniques.

In summary, the mass adjustment of the blade pitch physical model (gear and motor) and a wind speed estimation are the primary consideration. And the coupling effect of controller induced dynamic behaviour in terms of platform pitch motion damping (Goupee et al. 2017) and extra aerodynamic damping (e.g., negative damping phenomenon (Larsen and Hanson 2007; Thiagarajan and Dagher 2014)) which still does not have the final conclusion, because of the limited researches. 


\subsection{Experimental Facilities and Calibration Methods}

To accurately measure the coupling response of FOWTs under the action of both aerodynamic and hydrodynamic loads, a set of controlled wind field rectification system has to be specially designed for the experiment to achieve spatial and temporal uniformity. Wind generation techniques may not be feasible in an open basin (Martin et al. 2014), especially for less advanced facilities. To accurately measure the coupling response of FOWTs under wind and wave, a wind-making rectification system with a controllable wind field is often designed to achieve uniformity in space and time. Improved wind generation systems have been proposed by Courbois et al. (2011a, b), Newton et al. (2015) and Philippe et al. (2013).

Before the experiment, other key factors are calibrated which will influence the whole experiment directly, involving tuning the platform, tower and aerodynamic parameters. Wind turbine geometry, mass properties, aerodynamic losses and the drivetrain mechanical friction in the simulated rotor and blade model should be examined. Decay tests are required to determine approximate constants of the initial conditions. Through the decay test, the stiffness, mass and added mass, the moment of inertia and damping accuracy of the model system can be verified. Stewart et al. (2012) and Browning et al. (2014) proposed a method called further decay tests and also gave some details for calibration and validation (physical and numerical). The natural frequency of the tower can be tested by the hammer test. Rotor and nacelle parts are not included in the hammer test. However, the influence of the sensor and cable is not negligible. For this reason, the mass of the wind turbine has a certain difference from the design value in the basin model test. Yu et al. (2017) and Bredmose et al. (2017) discussed partly calibration in the Triple spar campaign. Based on the previous work of Duan et al. (2016a, b), Li et al. (2018a, b) proposed an improved deficient thrust force correction approach which used the wind to drive the rotor rather than the motor.

\section{Real-Time Hybrid Approach}

Under the premise mentioned above, many scholars selectively avoided the simulating aerodynamic issues when studying the dynamic responses of FOWTs, focusing mostly on the effects of hydrodynamic forces or they may use the original disk to replicate the required thrust force in a much easier way. With the limitations of methods and facilities, these practices were popular in early research. However, seldom details have been thoroughly opened to the public. Through the improvement of theoretical and numerical models' fidelity and increased computational power, the real-time hybrid approaches (RTHA) have been proposed recently. It consists of physical and virtual subsystems that can be defined as a combination of basin experiment and hardware-in-the-loop (HIL). A numerical model in HIL simulation accounted for the transient and degraded responses, interfacing with scale model through sensors and actuators (Plummer 2006). This presented the method applied in all aerodynamic load components (thrust force and torque) on a wind turbine model in a new way, while unlike previous similar champions, only satisfied thrust force.

In RTHA, the wind turbine or floating platform will be replaced with some actuation systems. And a full range of transient aero-hydro-servo-elastic dynamics force, which is calculated in a numerical model simulation in real-time, will be applied on the model by these actuators. A thorough introduction of the working mechanism of RTHA in the context of floating structures and proposes its use in basin experiment of FOWTs has been provided by Chabaud et al. (2013). Different from a usual numerical simulation, delays and dynamics are undesired compensation in this alternative approach which means one feedback-controlled facility was settled to emulate aerodynamic forces (Hall et al. 2018; Hall and Goupee 2018; Hall et al., 2014) or wave forces (Bayati et al. 2014; Bottasso et al. 2014; Filippo et al. 2014). The aero-elastic response of the tower and blades is usually neglected in basin experiment. However, these can be simulated with a scale model in software by using BEMT and beam bending models in RTHA. Additionally, this method created an easy way to effectively solve the wind generator techniques at model scale, and relatively simple in utilizing non-generic designs.

\subsection{Code Development}

It is because of the rapid development of software technology that it promoted the birth of RTHA. Moreover, hardware and software play significant roles in the experiment. Therefore, it is necessary to give a brief overview of numerical simulation before discussing RTHA. Currently, researchers have been exploiting numerous numerical simulation tools for analysing the full-scale FOWTs which can be classified into two categories (Liu et al. 2016): frequency domain and time domain analysis. Many new numerical simulation tools have been created in recent years and most related experiments are undergoing code-tocode or code-to-experiment validation, especially in hybrid basin experiment. This section will provide a brief introduction and summary of the numerical simulation tools.

\subsubsection{Frequency Domain Analysis}

Grant proposed BEMT to apply the aerodynamic forces of the wind turbine, based on the one-dimensional momentum theory proposed by Rankine et al. (Ingram 2005). According to Cordle and Jonkman (2011), BEMT is an aerodynamic model currently used to calculate aerodynamic loads. However, the presence of significant low-frequency motion in FOWTs 
makes the flow field around the blade more complex than a fixed wind turbine. Therefore, researchers have proposed many correction methods for this theory (Hansen 2015; Hansen et al. 2006): Prandtl's tip loss correction factor and Glauert's correction.

The calculation of the hydrodynamic load of FOWTs usually depends on the structure of the floater. For a spar type, the calculation of hydrodynamic loads is a complex coupling problem that requires consideration of incident wave excitation force, potential flow radiation damping and additional mass. In 1950, to simplify the computational complexity of the project, Morison et al. (1950) proposed the Morison empirical formula to solve the hydrodynamic load calculation of the floating structure. Subsequently, the formula is widely used in the calculation of hydrodynamic loads in cylinders (Faltinsen 1993; Wei et al. 2014). This formula is also the earliest model for hydrodynamic calculation of FOWTs (Faltinsen 1993; Maniar and Newman 1997). But it is mainly applied to the calculation of hydrodynamic loads of offshore fixed wind turbines. The Morison formula is primarily suitable for applications on small-scale structures since it ignores the memory effect of the free surface and uses G.I.Taylor's long-wave approximation to simplify the diffraction problem (Cummins 1962; Ogilvie 1964). All these make the Morison formula not applicable on large-scale structures. Later, the researchers tried to numerically analyse the FOWTs in the frequency domain under the linear assumption.

For linear systems, when a periodic load of a single frequency is applied to the system, such as a floating body under the action of a regular wave, the excitation response should be a single frequency. The response amplitude operator (RAO) defined in the traditional ship and ocean engineering is based on this linear input-output hypothesis to reflect the responses of the floating body by the wave excitation load. Therefore, for the traditional floating platform, the frequency function can be solved by direct frequency domain calculation to predict the responses of the floating body under the wave excitation load (Ma et al. 2014). However, for FOWTs, its normal operating state is subject to both wind and wave loads. And in the case of turbine blades rotating at a specific speed, the wave load of a single frequency can no longer be seen as a single input. At the same time, a single frequency wave load excitation can also result in multiple frequency responses. This nonlinear characteristic is mainly caused by the rotation effect of the blade and the system instability induced by the blade pitch controller (Jonkman et al. 2010).

Therefore, for FOWTs, first of all, the response of the system to wave excitation cannot directly solve the frequency function or the RAO from the traditional frequency domain equation. Secondly, when evaluating the responses of the system induced by wave excitation, the normal operation of the wind turbine, that is, the rotation effect of the blade and the wind load effect, cannot be ignored. This is determined by the system characteristics of the FOWTs itself. Otherwise, only the response characteristics of the wave load are considered. The forecast is of little significance in practice. To better evaluate the response of the system to wave excitation, Jonkman et al. (2010) proposed the concept of "effective RAO" with the definition of the traditional marine floating platform RAO.

Inspired by the technologies of offshore $O \& G$ industries in the field, some researchers have studied the dynamical characteristics of FOWTs using frequency domain analysis tools. For example, Lee (2005) and Wayman et al. (2006) performed a series of investigations on TLP and analysed shallow-drafted barge and the MIT/NREL TLP, respectively. Wang et al. (2017) proposed a frequency domain approach to analyse the coupling effects of FOWTs. However, FOWTs are the typical non-linear system which is not capable of modelling and involves the influence of coupling between aerodynamic loads, structural elastic deformation and the movement modes.

\subsubsection{Time Domain Analysis}

In traditional ocean engineering, the floating structure is considered to be a single rigid body, which can be used to establish the dynamic equation of the structure. And this rigid body must have no relative motion between the various mass points inside the structure. However, when the FOWTs is working, the rotor rotates continuously, and there are relative motions between the rotor, blade, nacelle structure and platform which do not meet the conditions for the single rigid body dynamic theory. Therefore, the FOWTs could be regarded as a fully coupled aero-hydro-servo-elastic model by solving the dynamical equations of numerous degrees of freedom (DOF) in the time domain. And the DOF of FOWTs' systems (except mooring system) mainly are:

- 6DOF motions of the platform.

- Modal coordinates of the elastic deformation of the tower in all directions.

- The rotation of the nacelle relative to the top of the tower.

- The rotation of the rotor relative to the nacelle.

- The rotation of each blade relative to the hub of the end of the transmission rotor.

- Modal coordinates of the elastic deformation of each blade.

To study a simple system consisting of a small number of rigid bodies, it is convenient and feasible to use any kind of mechanical method. However, for a plurality of rigid bodies, even systems containing flexible bodies, a more general mechanical model needs to be established. In multi-body systems, some objects are assumed to be rigid bodies, and some objects must consider flexible deformation. The mechanical model is called the rigid-flexible multi-body system. 
The traditional hybrid coordinate model ignores the quadratic coupling term when considering the coupling between the large-scale rigid body motion and the high-frequency elastic deformation motion of the flexible body at low frequencies, and directly uses the analysis results suitable for small deformation displacement in structural dynamics. It is not only unable to deal with the dynamic stiffening phenomenon brought by the rigid body motion to the flexible body but also causes the negative stiffness phenomenon when the largescale rigid body motion is very large or the flexible beam is long, which affects the solution of the flexible beam motion displacement. The longer the length of the flexible beam, the more obvious the phenomenon of dynamic stiffening, and the elastic deformation is reduced. Therefore, for the large and slender flexible structure, the coupling effect of high-order elastic deformation and large-scale rigid body motion should be considered. And also, it is because of non-linear behaviour, transient effects and coupling effect, which cannot be simulated accurately in frequency domain analysis. Therefore, the time domain analysis method has come into the mainstream gradually.

Karimirad and Moan (2011) conducted an extreme structural response and fatigue loads of a spar-type FOWTs. Bachynski et al. (2013) did the research on transient events in time domain analysis. In addition to special R\&D, some researchers made improvements from $O \& G$ industries or some other existing codes. For example, Jonkman and Buhl $\mathrm{Jr}$ (2005) added hydrodynamic mooring loads into FAST code which has been developed for onshore bottom-mounted wind turbines, originally by Wilson et al. (1999). Fylling et al. (2009) employed SIMO (structural dynamics and hydrodynamics) and RIFLEX (model mooring lines with FEM) to carry out the research, combined with a separate aerodynamic subroutine.

Several time domain numerical tools have been developed from commercially available general-purpose multi-body system (MBS) codes. ADAMS and SIMPACK have been used by combing with additional aerodynamic, mooring and hydrodynamic subroutines for Withee (2004) and Matha et al. (2011), respectively. Ormberg and Bachynski (2012) described the RIFLEX extension of aerodynamic load on elastic structural components. Also, aNySIM has been developed and validated by MARIN to provide clients with a more integrated simulation package including multi-body side-by-side, the mooring system and dynamic positioning capability studies (De Wilde et al. 2009; Naciri et al. 2007; Serraris 2009). Another integrated code DARwind has been proposed by Chen et al. (2019). And also some theoretical background can be found in his papers which also were verified code-toexperiments (Chen et al. 2017).

With the development of computer technology, computational fluid dynamics (CFD) has become one of the strong tools to analyse global dynamic responses of FOWTs. Zhao and Wan (2014) and Liu et al. (2015) conducted a series of investigations by their own CFD tool NAOE-FOAM-SJTU. And comparisons of wave load effects of TLP by combining potential flow theory approaches and CFD were conducted by Nematbakhsh et al. (2015). Tran et al. (2014) applied the CFD method to study the influence of periodic pitching motion on the aerodynamics of FOWTs and compared other calculation models. In the simulation of large-scale pitch motion, the CFD method has a smaller load than the traditional aerodynamic model and can be a more accurate calculation of the effects of unsteady loads and random motion of the platform. The Offshore Code Comparison Collaboration (OC3, OC4 and OC5) project (Jonkman and Musial 2010; Robertson and National Renewable Energy L 2014; Robertson et al. 2017) can be regarded as a series successful comparison.

In summary, the previous work has concluded the different numerical simulation tools in each module, based on Liu et al. (2016). Nonetheless, very limited studies have been performed that elaborate on the rigid-flexible coupling multibody methodologies implemented in FOWTs. And detailed test data hardly being openly available to the public.

The development of CFD technology has played a certain role in promoting the research of FOWTs. However, due to the high requirements of hardware or software, long time consumption and lack of accurate verification, compared with the traditional numerical simulation method, still need to be improved. Although some of these tools have been used in a wide range and even have been benchmarked through codeto-code check work, for instance, FAST and HAWC2, few of these numerical tools have been accepted consistently for their reliabilities if these tools are used solely to predict global responses of FOWTs. In addition, in the numerical tools, the coupling effect is truly a challenge to be considered in an integrated way. Due to some assumptions or simplifications introduced in theoretical calculations, such as hydrodynamic calculations without considering second-order wave forces, and potential flow calculations neglecting viscous effects, etc., it will bring inaccuracies in some aspects of the simulation results of numerical simulation tools. For example, the hydrodynamic calculation linearization cannot account for the second-order difference frequency wave force, which causes the oscillation of the surge, pitch and heave under wave excitation to be correctly simulated at the natural frequency; the second-order harmonic wave force cannot be considered. It is possible that the vibration of the tower at its natural frequency cannot be sufficiently excited. But this coupling effect can be reflected and obtained in a basin model test.

\subsection{Hybrid Basin Experiment}

A real-time hybrid method was first applied to the earthquake of civil engineers in the 1970s in Japan by Carrion and Spencer Jr (2007). They tried to validate the assumption of 
large-scale structural behaviour which can be realized and interface experiments with simultaneous simulation. And various pathfinder improved tremendously as this method became a criterion for buildings and bridges' damage simulation (Horiuchi et al., 1999; Nakashima et al., 1992). A detailed review up to 2007 has been given in Carrion and Spencer Jr (2007). A review of this RTHA has been applied to simulate aerodynamic forces within the automotive car industry, which was made by Plummer (2006) and the individual parts (de Klerk, 2009; Klerk et al., 2008; Li, 2014). The development of this method has been promoted in the USA by Shao and Griffith (2013) and in Europe by Pinto et al. (2004) as well. With the development of RTHA, the challenges arose because of its interaction between multi-disciplinary simulation including software, hardware, fabricating measurement, experimental methods, signal processing, control engineering and data acquisition which required instantaneity and precision for real-time coupling.

Some examples of each discipline's fundamental progress or advanced methods have been provided by Sauder et al. (2016) including control strategies (Carrion and Spencer Jr, 2007) and stability analyses (Kyrychko et al., 2006). The application of RTHA in renewable energy and marine technology can be found in Cao and Tahchiev (2013), Chabaud et al. (2013), Li et al. (2006), Munteanu et al. (2010), Signorelli et al. (2011) and references therein. The objective aerodynamic thrust and generator torque should be considered or actuated which are the most significant effects on floaters when using a modified numerical simulation.

As to gyroscopic moments, non-thrust loads (pitch and yaw moment, sway and heave force), dynamic torque and thrust directionality have been neglected in RTHA (Bachynski et al., 2015). Bachynski et al. (2016) and Sauder et al. (2016) also offered a brief review of the RTHA testing which is adopted for FOWTs' experiments by limiting a part of the environment to avoid the discussed scaling problem (Figure 4).

In their experiment, they proposed one method to apply wind-wave-induced forces and the blade pitch control algorithm by using a series of tensioned wires to connect the turbine and actuators to provide the transient simulated force rather than a ducted. The specific process of this hybrid method on a 1/30 scale 5-MW braceless semi-type wind turbine has been proposed in terms of qualification, quantification, possible error sources and performance of FOWTs. In the last stage, Berthelsen et al. (2016) introduced a methodology of using experimental data to calibrate the numerical model and quantify and mitigate equipment. Karimirad et al. (2017) used SIMA to extend previous work by Berthelsen et al. (2016) in terms of the BEM model for rotor forces and second-order loads compared with experimental data. In addition, coupled aerodynamic simulations were conducted to avoid potentially incorrect modelling of the aerodynamic damping (Stewart and Muskulus 2016a, b). Results of experimental data and full-scale numerical simulation from hybrid testing of 1/50th scale FOWTs have been provided by Hall et al. (2014) and five considerations of RTHA have been proposed:

- Actuator displacement.

- Velocity and acceleration envelopes.

- Actuator force envelopes.

- Motion tracking accuracy.

- Force actuation accuracy and system latency.

Bayati et al. (2013) performed a 2-DoF (Pitch and Surge motion) experimental rig-HexaFloat in a wind tunnel to simulate the motion of a $1 / 25$ scale DTU $10-\mathrm{MW}$ wind turbine model which combined hydrodynamic and aerodynamic loads within the LIFES50+ project (Bayati et al. 2016). Next year, HexaFloat (Figure 5) has been expanded to 6DOF (Bayati et al. 2014; Delbene et al. n.d.). In 2017, they proposed an aerodynamic design methodology and a scale model technology for a 1/75 scale DTU 10-MW wind turbine rotors (Bayati et al. 2017a, b).

In general, the technical issues and methodologies of this hybrid/HIL test can be found in Bayati et al. (2018a, b). More challenges for performing this method can be found in Bayati et al. $(2018 \mathrm{a}, \mathrm{b})$. In the former case, Bayati illustrated the methodology of blade design. But he did not put the turbine system in real water and simplified the 6DOF motions of the supporting platform to a large extent. But Bayati ignored the coupling effect between the blade pitch controller-induced instability of the floater and the aerodynamic load due to blade rotation and wave excitation. Therefore, it can be pointed out that the model test in a wind tunnel is a promising way to predict global responses of floating wind turbine but still in the face of many challenges.

Another real-time hybrid approach was validated by Hall et al. (2018), and Hall and Goupee (2018), which can be seen in Figure 6. In their experiment, an actuation system combined numerical wind turbine model was set to simulate the thrust force by winch and cables, pulling fore and aft on the nacelle. Three controls are integrated which was executed by changing cable length.

He also demonstrated the benefit and possible disadvantages of some hybrid approaches and compared with physical wind-wave tests which show a satisfactory agreement. However, some other aerodynamic force and moment have been neglected. And also, the mean value of platform surge motion has a great difference up to $17 \%$ (no wind) and $14 \%$ (steady wind), respectively. This may be due to unidirectional dynamic forces on the nacelle by the actuation system. More specifications and detailed methodologies have been given in Hall et al. (2018).

Vittori et al. (2018) proposed one hybrid experimental method by using software-in-the-loop (SIL) method. 


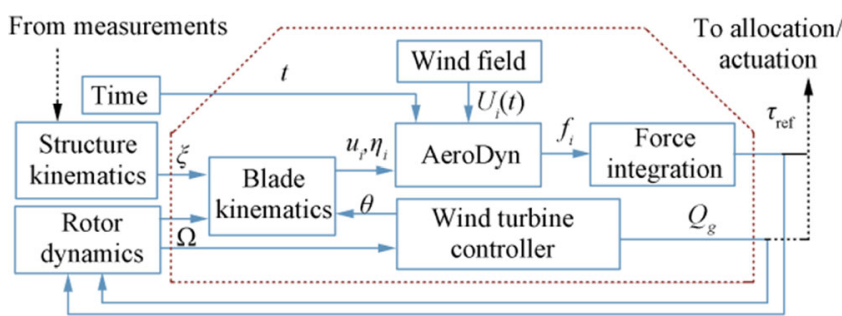

Figure 4 Block diagram of the numerical substructure (Bachynski et al., 2016)

Different from HIL, SIL validates that generated code has the same behaviour as tested in the model simulation and does not need a hardware interface. This SIL method was applied on OC4 to integrate the aerodynamic performance. The results of all the cases in the experiment are compared with numerical software. However, since the setting of the data type accuracy is done in the SIL, all the calculations inevitably cause calculation errors.

In summary, the scalability and fidelity of basin experiment can be improved by RTHA potentially. The dissimilar scaling issue can be avoided and any scale can be modelled. Requirements of experimental facilities can be reduced and blade pitch control can be modelled without the limitations of small-scale actuation. These make the model test of FOWTs more accessible and flexible to researchers. However, there still have been possible disadvantages. The significant difficulty in numerical modelling of FOWTs is the accurate estimation of the influence of sensor cables (Coulling et al. 2013). Since the model of FOWTs is very light, the influence of the sensor cable can be said to be non-negligible and even very important. In addition, sensor cables of various test institutions in the world are not the same, and the arrangement of cables in basin test cannot be unified. The influence of cables may even be non-linear, so it is difficult to accurately estimate the impact of the cable. The errors may also arise due to the

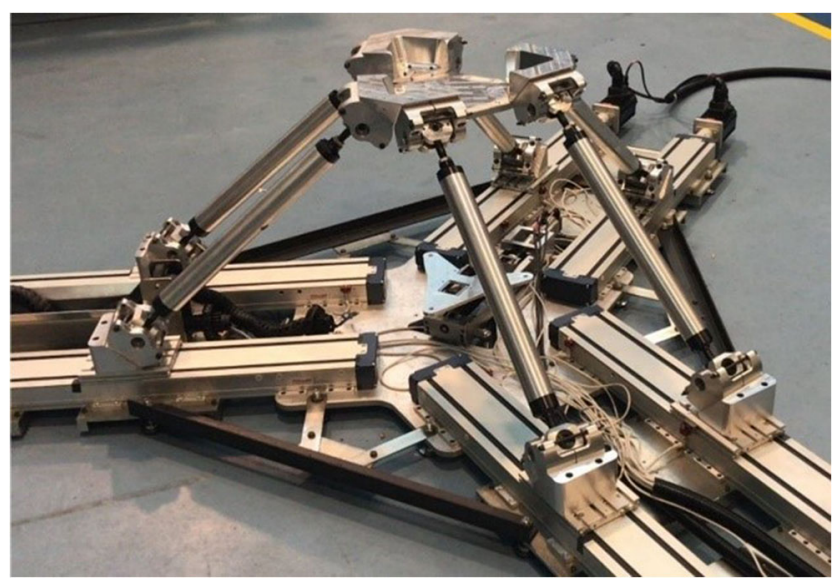

Figure 5 Hexafloat robot (Bayati et al., 2017a, b)

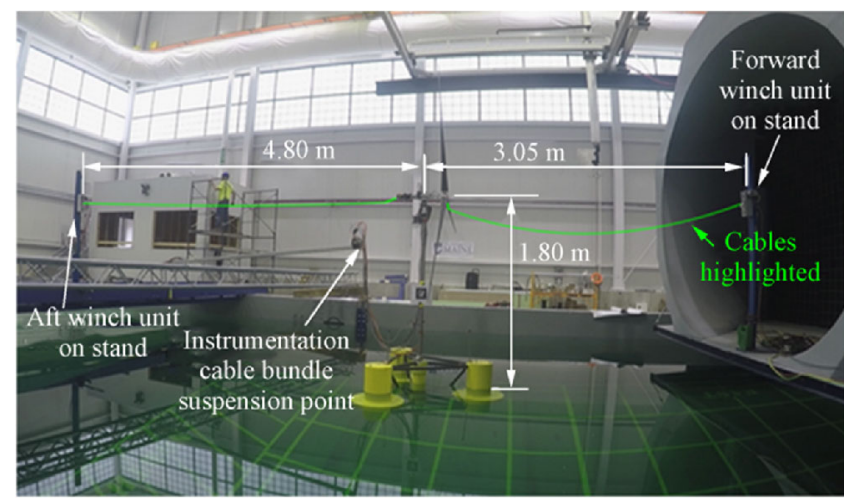

Figure 6 Arrangement of cable system in basin (Hall and Goupee 2018)

various inaccuracies and delays. And also, the quality of virtual subsystems will influent the results. In addition, almost all the theories are adopted in numerical simulation which relies on assumptions (Farrugia et al. 2016; Jeon et al. 2014; Sebastian and Lackner 2013). Most importantly, more problems (design, manufacture and optimization) may come due to the need to find alternatives actuation system.

\section{Conclusions}

\subsection{Summary}

This paper aims to present academic literature pertaining to provide comparisons and conclusions to make a further footstone for proposing an efficient, economic and simplified method to predict the global dynamic responses of FOWTs. Three methods (on-site measurement, basin model test and numerical analysis) to validate the technical and economic feasibility of FOWTs have been compared and discussed the importance of experimenting to validate the full scale. Some previous work and typical industrial projects combined model tests have been introduced. A summary of several model tests to optimize the experimental methods have been provided in terms of drag disk, re-design rotor and blade, and hybrid method briefly. Some common challenges have been concluded: scaling issues, blade pitch control strategies, experimental facilities and calibration methods. Brief code development has been provided. And some new real-time hybrid approaches have been discussed also which are conducted by one feedback-controlled facility to emulate aerodynamic forces or wave forces, the scalability and fidelity of the basin experiment can be improved by RTHA potentially.

\subsection{Future Work}

With the commercialization of FOWTs and the promotion of its engineering applications, more academic issues will 
emerge. For example, the current OC6 project aims to understand the reason for the under-prediction of loads/motion in floating semisubmersibles in pitch/surge natural frequencies. In addition, it is also aimed to develop and employ more rigorous validation practices through OC6, in terms of identifying a specific validation objective, using metrics to assess validation success and calculating associated experimental uncertainty of metrics.

Furthermore, with the maturity of experimental technology and the improvement of hardware and software equipment, the method of RTHA will be applied, promoted and innovated to a greater degree. The dissimilarity of the scaling issue can be solved. Requirements of experimental facilities can be lowered and blade pitch control can be simulated effectively. These make the model test of FOWTs more affordable to researchers.

However, there are still some challenges in basin experiment technology, for instance, testing errors may arise due to various inaccuracies and delays and the theories are adopted in the numerical simulation. Most importantly, more problems (design, manufacture and optimization) may come due to the need to find alternatives actuation system. All of the above may be the problems to be solved in the future application of the RTHA method.

Open Access This article is licensed under a Creative Commons Attribution 4.0 International License, which permits use, sharing, adaptation, distribution and reproduction in any medium or format, as long as you give appropriate credit to the original author(s) and the source, provide a link to the Creative Commons licence, and indicate if changes were made. The images or other third party material in this article are included in the article's Creative Commons licence, unless indicated otherwise in a credit line to the material. If material is not included in the article's Creative Commons licence and your intended use is not permitted by statutory regulation or exceeds the permitted use, you will need to obtain permission directly from the copyright holder. To view a copy of this licence, visit http://creativecommons.org/licenses/by/4.0/.

\section{References}

Ahn H-J, Shin H (2017) Model test and numerical simulation of OC3 spar type floating offshore wind turbine. Int J Naval Archit Ocean Eng 11(1): $1-10$

Ai Y, Wan D (2017) Coupling numerical analysis of aero-hydro-mooring system of floating wind turbine system. J Jiangsu Univ Sci Technol 31(5):612-619

Amate J, Víctor L, Martín DD, García L, Pablo M, Alonso G (2014) Iberdrola Ingeniería TLPWIND a smart way to drive costs down. Proceedings of the EWEA

Arakawa C (2015) Curreent status of Janpanese offshore wind R\&D progects and its roadmap. The University of Tokyo, WWEC 2015

Aubault A, Cermelli CA, Roddier DG (2006) Structural design of a semisubmersible platform with water-entrapment plates based on a timedomain hydrodynamic algorithm coupled with finite-elements. The Sixteenth International Offshore and Polar Engineering Conference
Aubault A, Cermelli C, Roddier D (2007) Parametric optimization of a semi-submersible platform with heave plates. ASME 2007 26th international conference on offshore mechanics and Arctic engineering, 471-478

Aubault A, Cermelli C, Roddier D (2009) WindFloat: a floating foundation for offshore wind turbines - part III: structural analysis. ASME 2009 28th international conference on ocean, offshore and Arctic engineering, 213-220

Bachynski EE, Chabaud V, Sauder T (2015) Real-time hybrid model testing of floating wind turbines: sensitivity to limited actuation. Energy Procedia 80:2-12

Bachynski EE, Etemaddar M, Kvittem MI, Luan C, Moan T (2013) Dynamic analysis of floating wind turbines during pitch actuator fault, grid loss, and shutdown. Energy Procedia 35:210-222

Bachynski EE, Thys M, Sauder T, Chabaud V, Sæther LO (2016) Realtime hybrid model testing of a Braceless semi-submersible wind turbine: part II-experimental results. ASME 201635 th International Conference on Ocean, Offshore and Arctic Engineering, V006T009A040-V006T009A040

Bahramiasl S, Abbaspour M, Karimirad M (2018) Experimental study on gyroscopic effect of rotating rotor and wind heading angle on floating wind turbine responses. Int J Environ Sci Technol:1-14

Bak C, Zahle F, Bitsche R, Kim T, Yde A, Henriksen LC, Hansen M, Blasques J, Gaunaa M, Natarajan A (2013) Description of the DTU $10 \mathrm{MW}$ reference wind turbine. DTU wind Energy report-I-0092. Technical University of Denmark, Fredericia

Bakka T, Karimi HR (2012) Robust dynamic output feedback control synthesis with pole placement constraints for offshore wind turbine systems. Math Probl Eng 2012:1-18

Bayati I, Belloli M, Facchinetti A (2013) Wind tunnel tests on floating offshore wind turbines: a proposal for hardware-in-the-loop approach to validate numerical codes. Wind Eng 37(6):557-568

Bayati I, Gueydon S, Belloli M (2015) Study of the effect of water depth on potential flow solution of the OC4 semisubmersible floating offshore wind turbine. Energy Procedia 80:168-176

Bayati I, Belloli M, Bernini L, Zasso A (2017a) Aerodynamic design methodology for wind tunnel tests of wind turbine rotors. J Wind Eng Ind Aerodyn 167:217-227

Bayati I, Facchinetti A, Fontanella A, Belloli M (2018a) 6-DoF hydrodynamic Modelling for wind tunnel hybrid/HIL tests of FOWT: the real-time challenge. In International Conference on Offshore Mechanics and Arctic Engineering (Vol. 51319, p. V010T09A078). American Society of Mechanical Engineers

Bayati I, Belloli M, Ferrari D, Fossati F, Giberti H (2014) Design of a 6DoF robotic platform for wind tunnel tests of floating wind turbines. Energy Procedia 53:313-323

Bayati I, Belloli M, Bernini L, Giberti H, Zasso A (2017b) Scale model technology for floating offshore wind turbines

Bayati I, Facchinetti A, Fontanella A, Giberti H, Belloli M (2018b) A wind tunnel/HIL setup for integrated tests of floating offshore wind turbines. Journal of Physics: Conference Series:052025

Bayati I, Belloli M, Bernini L, Fiore E, Giberti H, Zasso A (2016) On the functional design of the DTU10 MW wind turbine scale model of LIFES50+ project. J Phys Conf Ser 753(5):052018

Berthelsen PA, Bachynski EE, Karimirad M, Thys M (2016) Real-time hybrid model tests of a braceless semi-submersible wind turbine: part III-calibration of a numerical model. ASME 2016 35th International Conference on Ocean, Offshore and Arctic Engineering, V006T009A047-V006T009A047

Blusseau P, Patel MH (2012) Gyroscopic effects on a large vertical axis wind turbine mounted on a floating structure. Renew Energy 46:3142

Bottasso CL, Campagnolo F, Petrović V (2014) Wind tunnel testing of scaled wind turbine models: beyond aerodynamics. J Wind Eng Ind Aerodyn 127:11-28 
Bredmose H, Mikkelsen R, Hansen AM, Laugesen R, Heilskov N, Jensen B, Kirkegaard J (2015) Experimental study of the DTU 10 MW wind turbine on a TLP floater in waves and wind. EWEA Offshore Conference, Copenhagen

Bredmose H, Lemmer F, Borg M, Pegalajar-Jurado A, Mikkelsen RF, Larsen TS, Fjelstrup T, Yu W, Lomholt AK, Boehm L (2017) The triple spar campaign: model tests of a 10MW floating wind turbine with waves, wind and pitch control. Energy Procedia 137:58-76

Brown DK (2006) The way of a ship in the midst of the sea: the life and work of William Froude. Penzance: Periscope

Browning JR, Jonkman J, Robertson A, Goupee AJ (2014) Calibration and validation of a spar-type floating offshore wind turbine model using the FAST dynamic simulation tool. Journal of Physics: Conference Series:012015

Bulder B, van Hees MT, Henderson A, Huijsmans RHM, Pierik JTG, Snijders EJB, Wijnants GH, Wolf MJ (2002) Studie naar haalbaarheid van en randvoorwaarden voor drijvende offshore windturbines. ECN, MARIN, Lagerwey the Windmaster, TNO, TUD, MSC

Butterfield S, Musial W, Jonkman J, Sclavounos P (2007) Engineering challenges for floating offshore wind turbines (No. NREL/CP-50038776). National Renewable Energy Lab.(NREL), Golden, CO (United States)

Cao Y, Tahchiev G (2013) A study on an active hybrid decomposed mooring system for model testing in ocean basin for offshore platforms. ASME 2013 32nd International Conference on Ocean, Offshore and Arctic Engineering, V001T001A080-V001T001A080

Cao Y, Tang Y, Tao H, Qin Y (2013) Design of floating foundation of semi-submersible wind turbine and study on amplitude-frequency motion characteristics. Mar Eng 2:61-67

Carrion JE, Spencer Jr BF (2007) Model-based strategies for real-time hybrid testing. Newmark structural Engineering Laboratory. University of Illinois at Urbana-Champaign. Report No. 1940-9826

Cermelli C, Roddier D, Aubault A (2009) WindFloat: a floating foundation for offshore wind turbines - part II: hydrodynamics analysis, vol 43444, pp 135-143

Cermelli C, Aubault A, Roddier D, McCoy T (2010) Qualification of a semi-submersible floating foundation for multi-megawatt wind turbines. Offshore Technology Conference

Cermelli CA, Roddier DG (2005) Experimental and numerical investigation of the stabilizing effects of a water-entrapment plate on a Deepwater minimal floating platform. ASME 2005 24th international conference on offshore mechanics and Arctic engineering, 517525

Cermelli CA, Roddier DG, Busso CC (2004) MINIFLOAT: A novel concept of minimal floating platform for marginal field development. Proceedings of the The Fourteenth International Offshore and Polar Engineering Conference

Cermelli CA, Roddier DG, Aubault A (2008) Remote power generation for deployment of subsea technologies in deepwater marginal fields. Offshore 68(1):52

Chabaud V, Steen S, Skjetne R (2013) Real-time hybrid testing for marine structures: challenges and strategies. Proceedings of the ASME 2013 32nd International Conference on Ocean, Offshore and Arctic Engineering, V005T006A021-V005T006A021

Chakrabarti S (1998) Physical model testing of floating offshore structures. Dynamic Positioning Conference, 1-33

Chakrabarti S (2005) Handbook of offshore engineering (2-volume set). Elsevier, Amsterdam

Chen J, Hu Z, Liu G, Tang Y (2017) Comparison of different dynamic models for floating wind turbines. J Renew Sustain Energy 9(6): 063304

Chen J, Hu Z, Wan D, Xiao Q (2018) Comparisons of the dynamical characteristics of a semi-submersible floating offshore wind turbine based on two different blade concepts. Ocean Eng 153:305-318
Chen J, Hu Z, Liu G, Wan D (2019) Coupled aero-hydro-servo-elastic methods for floating wind turbines. Renew Energy 130:139-153

Cheng P, Wan D (2017) Numerical analysis of the influence of towers on wind turbine in aerodynamic performance based on overlapping grid method. Res Progr Hydrodynam 32(1):32r39

Christiansen S, Bak T, Knudsen T (2013) Damping wind and wave loads on a floating wind turbine. Energies 6(8):4097-4116

Chujo T, Minami Y, Nimura T, Ishida S (2013) Experimental study for spar type floating offshore wind turbine with blade-pitch control. Proceedings of the ASME 2013 32nd International Conference on Ocean, Offshore and Arctic Engineering, V008T009A034V008T009A034

Cordle A, Jonkman J (2011) State of the art in floating wind turbine design tools. Proceedings of the Twenty-first International Offshore and Polar Engineering Conference

Coulling AJ, Goupee AJ, Robertson AN, Jonkman JM, Dagher HJ (2013) Validation of a FAST semi-submersible floating wind turbine numerical model with DeepCwind test data. J Renew Sustain Energy 5(2):023116

Courbois A (2013) Étude expérimentale du comportement dynamique d'une éolienne offshore flottante soumise à l'action conjuguée de la houle et du vent Ecole Centrale de Nantes (ECN)

Courbois A, Ferrant P, Flamand O, Rousset J-M (2011a) Wind generation on wave tank for floating offshore wind turbine applications. Proceedings of the 13th International Conference on Wind Engineering, Amsterdam

Courbois A, Flamand O, Toularastel JL, Ferrant P, Rousset JM (2011b) Applying relevant wind generation techniques to the case of floating wind turbines. Proceedings of the Sixth European and African Conference on Wind Engineering (EACWE), Nantes, France, 7-13

Cummins WE (1962) The impulse response function and ship motions. David Taylor Model Basin, Washington DC

de Klerk D (2009) Dynamic response characterization of complex systems through operational identification and dynamic substructuring. Delft University of Technology, The Netherlands

de Ridder E-J, Otto W, Zondervan G-J, Huijs F, Vaz G (2014) Development of a scaled-down floating wind turbine for offshore basin testing. Proceedings of the ASME 2014 33rd International Conference on Ocean, Offshore and Arctic Engineering, V09AT09A027-V009AT009A027

de Ridder E, Otto W, Zondervan G, Savenije F, Huijs FA (2013) State of the art model testing techniques for floating wind turbines. EWEA Offshore, Frankfurt, pp 19-21

De Wilde JJ, Van Dijk AW, van den Berg J, Dekker J (2009) Direct time domain downtime assessment for LNG operations using computer cluster. Proceedings of the Nineteenth International Offshore and Polar Engineering Conference

Delbene L, Bayati I, Facchinetti A, Fontanella A, Belloli M (n.d.) A 6DoF hydrodynamic model for real time implementation in hybrid testing

Du W, Zhao Y, He Y, Liu Y (2016) Design, analysis and test of a model turbine blade for a wave basin test of floating wind turbines. Renew Energy 97:414-421

Duan F, Hu Z, Niedzwecki JM (2016a) Model test investigation of a spar floating wind turbine. Mar Struct 49:76-96

Duan F, Hu Z, Liu G, Wang J (2016b) Experimental comparisons of dynamic properties of floating wind turbine systems based on two different rotor concepts. Appl Ocean Res 58:266-280

Faltinsen O (1993) Sea loads on ships and offshore structures. Cambridge university press, Cambridge

Farrugia R, Sant T, Micallef D (2014) Investigating the aerodynamic performance of a model offshore floating wind turbine. Renew Energy 70:24-30

Farrugia R, Sant T, Micallef D (2016) A study on the aerodynamics of a floating wind turbine rotor. Renew Energy 86:770-784 
Fernandez J, Laidler A, Izarra J, Innovation M, Murueta DBM (2013) Design considerations of a semisubmersible platform for offshore wind turbines In Proceedings of the EWEA Offshore

Filippo C, Carlo LB, Paolo B (2014) Design, manufacturing and characterization of aero-elastically scaled wind turbine blades for testing active and passive load alleviation techniques within a ABL wind tunnel. J Phys Conf Ser 524(1):012061

Forward F (2014) Fukushima floating offshore wind farm demonstration project. Fukushima Offshore Wind Consortium, Fukushima

Fowler MJ, Kimball RW, Thomas DA, Goupee AJ (2013) Design and testing of scale model wind turbines for use in wind/wave basin model tests of floating offshore wind turbines. Proceedings of the ASME 2013 32nd International Conference on Ocean, Offshore and Arctic Engineering, V008T009A004-V008T009A004

Fujiwara H, Tsubogo T, Nihei Y (2011) Gyro effect of rotating blades on the floating wind turbine platform in waves. Proceedings of the The Twenty-first International Offshore and Polar Engineering Conference

Fukumoto Y, Moriya Y, Tsuchiya K, Hara M, Suzuki H (2006) A study of floating offshore wind turbine systems. Part III investigation of reinforced concrete spar-buoy for offshore wind turbine. Proceedings of the Proceedings of 28th Wind Energy Utilization Symposium, Tokyo, 204-207

Fulton G, Malcolm D, Moroz E (2006) Design of a semi-submersible platform for a $5 \mathrm{MW}$ wind turbine. Proceedings of the 44th AIAA Aerospace Sciences Meeting and Exhibit, 997

Fylling I, Mo K, Merz K, Luxcey N (2009) Floating wind turbineresponse analysis with rigid-body model. Proceedings of the European Offshore Wind Conference and Exhibition, Stockholm, Sweden

Gao Z, Moan T, Wan L, Michailides C (2016) Comparative numerical and experimental study of two combined wind and wave energy concepts. J Ocean Eng Sci 1(1):36-51

González SF, Diaz-Casas V (2016) Present and future of floating offshore wind. Floating Offshore Wind Farms:1-22

Goupee AJ, Kimball RW, Dagher HJ (2017) Experimental observations of active blade pitch and generator control influence on floating wind turbine response. Renew Energy 104:9-19

Goupee AJ, Koo B, Lambrakos K, Kimball R (2012) Model tests for three floating wind turbine concepts. Proceedings of the Offshore Technology Conference

Goupee AJ, Fowler MJ, Kimball RW, Helder J, de Ridder E-J (2014a) Additional wind/wave basin testing of the DeepCwind semisubmersible with a performance-matched wind turbine(45547), V09BT09A026

Goupee AJ, Koo BJ, Kimball RW, Lambrakos KF, Dagher HJ (2014b) Experimental comparison of three floating wind turbine concepts. J Offshore Mech Arct Eng 136(2):020906-020909

Gueydon S (2016) Aerodynamic damping on a semisubmersible floating foundation for wind turbines. Energy Procedia 94:367-378

Gueydon S, Xu W (2011) Floating wind turbine motion assessment. Proc Oceans 2011:1-10

Hall M, Goupee AJ (2018) Validation of a hybrid modeling approach to floating wind turbine basin testing. Wind Energy 21(6):391-408

Hall M, Moreno J, Thiagarajan K (2014) Performance specifications for real-time hybrid testing of 1: 50-scale floating wind turbine models. ASME 2014 33rd International Conference on Ocean, Offshore and Arctic Engineering, V09BT09A047-V009BT009A047

Hall M, Goupee A, Jonkman J (2018) Development of performance specifications for hybrid modeling of floating wind turbines in wave basin tests. J Ocean Eng Marine Energy 4(1):1-23

Hansen AM, Laugesen R, Bredmose H, Mikkelsen R, Psichogios N (2014) Small scale experimental study of the dynamic response of a tension leg platform wind turbine. J Renew Sustain Energy 6(5): 053108

Hansen MOL (2015) Aerodynamics of wind turbines. Routledge
Hansen MOL, Sørensen JN, Voutsinas S, Sørensen N, Madsen HA (2006) State of the art in wind turbine aerodynamics and aeroelasticity. Prog Aerosp Sci 42(4):285-330

Hara N, Tsujimoto S, Nihei Y, Iijima K, Konishi K (2017) Experimental validation of model-based blade pitch controller design for floating wind turbines: system identification approach. Wind energy 20(7): 1187-1206

Henderson AR, Witcher D (2010) Floating offshore wind energy - a review of the current status and an assessment of the prospects. Wind Eng 34(1):1-16

Heronemus WE (1972) Pollution-free energy from offshore winds. Proceedings of the 8th Annual Conference and Exposition. Marine Technology Society, Washington, DC

Hill JS (2018). Hywind Scotland, World's first floating wind farm, Performing Better Than Expected, 2019(11/7)

Horiuchi T, Inoue M, Konno T, Namita Y (1999) Real-time hybrid experimental system with actuator delay compensation and its application to a piping system with energy absorber. Earthq Eng Struct Dyn 28(10):1121-1141

Hu Z, Li L, Wang J, Hu Q, Shen M (2016) Dynamic responses of a semitype offshore floating wind turbine during normal state and emergency shutdown. China Ocean Eng 30(1):97-112

Huang Y, Cheng P, Wan D (2017) Computation and analysis of aerohydrodynamics of floating wind turbine with different tip speed. Proceedings of the 18th China Ocean Engineering Symposium

Huijs F, de Ridder E-J, Savenije F (2014) Comparison of model tests and coupled simulations for a semi-submersible floating wind turbine. Proceedings of the ASME 2014 33rd International Conference on Ocean, Offshore and Arctic Engineering, V09AT09A012V009AT009A012

Huijs F, Mikx J, Savenije F, de Ridder E-J (2013) Integrated design of floater, mooring and control system for a semi-submersible floating wind turbine. EWEA Offshore, Vienna

Iijima K, Kawai M, Nihei Y, Murai M, Ikoma T (2013) Conceptual design of a single-point-moored FOWT and tank test for its motion characteristics. Proceedings of the ASME 2013 32nd International Conference on Ocean, Offshore and Arctic Engineering, V008T009A079-V008T009A079

Ingram G (2005) Wind turbine blade analysis using the blade element momentum method version 1.0. School of Engineering, Durham University, UK

Ishida S, Kokubun K, Nimura T, Utsunomiya T, Sato I, Yoshida S (2013) At-sea experiment of a hybrid spar type offshore wind turbine. Proceedings of the ASME 2013 32nd International Conference on Ocean, Offshore and Arctic Engineering, V008T009A035V008T009A035

Ishihara T, Waris M, Sukegawa H (2009) A study on influence of heave plate on dynamic response of floating offshore wind turbine system. Proceedings of the Proceedings of the 3rd European Offshore Wind Conference and Exhibition, Stockholm, Sweden, 14-16

Ishihara T, Phuc PV, Sukegawa H, Shimada K, Ohyama T (2007) A study on the dynamic response of a semi-submersible floating offshore wind turbine system part 1: a water tank test. Proceedings of the proceedings of the 12th international conference on, 2511-2518

Ishihara T, Phuc PV, Sukegawa H, Shimada K, Ohyama T, Miyagawa M (2006) A study of floating offshore wind turbine systems part II: development of a lightweight semi-submersible floating system. Proceedings of the Proceedings of the 28th Wind Energy Utilization Symposium, Tokyo, Japan, 200-203

Jain A, Robertson AN, Jonkman JM, Goupee AJ, Kimball RW, Swift AHP (2012) FAST code verification of scaling laws for DeepCwind floating wind system tests: preprint. Golden, National Renewable Energy Laboratory (NREL)

James R, Ros MC (2015) Floating offshore wind: market and technology review. The Carbon Trust 
Jamieson P (2018) Innovation in wind turbine design. John Wiley \& Sons, New York

Jeon M, Lee S, Lee S (2014) Unsteady aerodynamics of offshore floating wind turbines in platform pitching motion using vortex lattice method. Renew Energy 65:207-212

Jin F, Teng B (2016) Time-domain coupling calculation method for motion response of offshore floating wind turbine. Grid Clean Energy 32(8):93-99

Jonkman J (2008) Influence of control on the pitch damping of a floating wind turbine. Proceedings of the 46th AIAA Aerospace Sciences Meeting and Exhibit, 1306

Jonkman J, Sclavounos P (2006) Development of fully coupled aeroelastic and hydrodynamic models for offshore wind turbines. Proceedings of the 44th AIAA Aerospace Sciences Meeting and Exhibit, 995

Jonkman J, Musial W (2010) Offshore code comparison collaboration (OC3) for IEA Wind Task 23 offshore wind technology and deployment. National Renewable Energy Lab. (NREL), Golden, CO (United States)

Jonkman J, Butterfield S, Musial W, Scott G (2009) Definition of a 5MW reference wind turbine for offshore system development. National Renewable Energy lab.(NREL), Golden, CO (United States)

Jonkman J, Larsen T, Hansen A, Nygaard T, Maus K, Karimirad M, Gao Z, Moan T, Fylling I (2010) Offshore Code Comparison Collaboration within IEA Wind Task 23: Phase IV Results Regarding Floating Wind Turbine Modeling; Preprint. National Renewable Energy Lab.(NREL), Golden, CO (United States)

Jonkman JM (2009) Dynamics of offshore floating wind turbinesmodel development and verification. Wind Energy 12(5):459-492

Jonkman JM, Buhl ML Jr (2005) Fast user's guide-updated august 2005. National Renewable Energy Laboratory (NREL), Golden, CO

Jonkman JM, National Renewable Energy L (2010) Definition of the floating system for Phase IV of OC3

José A, Faisal B, Marta G, Joseba G, Xabier M, Felix K, Tor AN (2014) Aerodynamic thrust modelling in wave tank tests of offshore floating wind turbines using a ducted fan. J Phys Conf Ser 524(1): 012089

Karimirad M (2011) Stochastic dynamic response analysis of spar-type wind turbines with catenary or taut mooring systems

Karimirad M, Moan T (2011) Extreme dynamic structural response analysis of catenary moored spar wind turbine in harsh environmental conditions. J Offshore Mech Arct Eng 133(4):041103

Karimirad M, Bachynski EE, Berthelsen PA, Ormberg H (2017) Comparison of real-time hybrid model testing of a Braceless semisubmersible wind turbine and numerical simulations. Proceedings of the ASME 2017 36th International Conference on Ocean, Offshore and Arctic Engineering, V010T009A061-V010T009A061

Kimball R, Goupee AJ, Fowler MJ, de Ridder E-J, Helder J (2014) Wind/ wave basin verification of a performance-matched scale-model wind turbine on a floating offshore wind turbine platform. Proceedings of the ASME 2014 33rd International Conference on Ocean, Offshore and Arctic Engineering, V09BT09A025-V009BT009A025

Kitamura F, Kokubun K, Ohkawa Y, Yago K (2006) Wind characteristics on Sagami bay and examination on wind turbine for ocean use, 181191

Klerk D, Rixen DJ, Voormeeren SN (2008) General framework for dynamic substructuring: history, review and classification of techniques. AIAA J 46(5):1169-1181

Knauer A, Hanson TD, Skaare B (2006) Offshore wind turbine loads in deep-water environment. EWEC 2006

Koh J, Ng E, Robertson A, Jonkman J, Driscoll F (2016) Validation of a FAST Model of the SWAY Prototype Floating Wind Turbine. National Renewable Energy Lab.(NREL), Golden, CO (United States)
Kokubun K, Ishida S, Nimura T, Chujo T, Yoshida S, Utsunomiya T (2012) Model experiment of a SPAR type offshore wind turbine in storm condition. Proceedings of the ASME 2012 31st International Conference on Ocean, Offshore and Arctic Engineering, 569-575

Koo BJ, Goupee AJ, Kimball RW, Lambrakos KF (2014) Model tests for a floating wind turbine on three different floaters. J Offshore Mech Arct Eng 136(2):020907-020911

Kyrychko YN, Blyuss KB, Gonzalez-Buelga A, Hogan SJ, Wagg DJ (2006) Real-time dynamic substructuring in a coupled oscillatorpendulum system. Proceedings of the Proceedings of the Royal Society of London A: Mathematical, Physical and Engineering Sciences: $1271-1294$

Lackner Matthew A (2013) An investigation of variable power collective pitch control for load mitigation of floating offshore wind turbines. Wind energy 16(4):519-528

Laino DJ, Hansen AC (2002) Aerodyn user's guide. Available electronically at https://www.wind/designcodes/simulators/aerodyn/ AeroDyn.pdf

Larsen TJ, Hanson TD (2007) A method to avoid negative damped low frequent tower vibrations for a floating, pitch controlled wind turbine. Proceedings of the Journal of Physics: Conference Series, 012073

Laugesen R, Hansen AM (2015) Experimental study of the dynamic response of the DTU 10MW wind turbine on a tension leg platform. DTU Wind Energy. Phys Conf Ser 753:092007

Le Boulluec M, Ohana J, Martin A, Houmard A (2013) Tank testing of a new concept of floating offshore wind turbine. Proceedings of the ASME 2013 32nd International Conference on Ocean, Offshore and Arctic Engineering, V008T009A100-V008T009A100

Lee KH (2005) Responses of floating wind turbines to wind and wave excitation. Thesis (S.M.)-Massachusetts Institute of Technology, Dept. of Ocean Engineering

Li G (2014) A generic dynamically substructured system framework and its dual counterparts. IFAC Proceed 47(3):10101-10106

Li H, Hu Z, Wang J, Meng X (2018a) Short-term fatigue analysis for tower base of a spar-type wind turbine under stochastic wind-wave loads. Int J Naval Architec Ocean Eng 10(1):9-20

Li H, Steurer M, Shi KL, Woodruff S, Zhang D (2006) Development of a unified design, test, and research platform for wind energy systems based on hardware-in-the-loop real-time simulation. IEEE Trans Ind Electron 53(4):1144-1151

Li J, Tang Y, Qu X, Li Y, Zhang R (2017) Impact of downtime caused by pitcher failure on the motion of offshore trussed spar wind turbines. Ship Eng 39(3):49-54

Li L, Gao Y, Hu Z, Yuan Z, Day S, Li H (2018b) Model test research of a semisubmersible floating wind turbine with an improved deficient thrust force correction approach. Renew Energy 119:95-105

Lindeberg E, Svendsen HG, Uhlen K (2012) Smooth transition between controllers for floating wind turbines. Energy Procedia 24:83-98

Liu L, Guo Y, Zhao H, Tang Y (2017a) Dynamic modeling, simulation and experimental study of floating vertical Axis wind turbine. Acta Mech Sinica 49(2):299-307

Liu L, Zhao H, Yuan R, Huang X, Li Y (2018) Modeling and simulation of rigid-flexible coupled multibody dynamics of H-type floating vertical axis wind turbine. Mar Eng 36(3):1-9

Liu Y, Peng Y, Wan D (2015) Numerical investigation on interaction between a semi-submersible platform and its mooring system. Proceedings of the ASME 2015 34th International Conference on Ocean, Offshore and Arctic Engineering, V007T006A071V007T006A071

Liu Y, Li S, Yi Q, Chen D (2016) Developments in semi-submersible floating foundations supporting wind turbines: a comprehensive review. Renew Sust Energ Rev 60:433-449

Liu Y, Qing X, Incecik A, Peyrard C, Wan D (2017b) Establishing a fully coupled CFD analysis tool for floating offshore wind turbines. Renew Energy 112:280-301 
Lu D, Biao W, Zhiying X, Xiaoping S (2016a) Research on conceptual design and performance of reinforced concrete floating wind turbine platform. J Huazhong Univ Sci Technol 44(1)

Lu D, Songxiong W, Wenjie Z, Xiaoping S (2018) Impact of wind and wave angle change on mooring of offshore floating wind turbines. J Civ Eng Manag 2018:1-6

Lu D, Zijia T, Biao W, Xiaoping S, Haitao W (2016b) Research on motion characteristics and mooring system of semi-submersible floating fan. Ship Eng 38(8):1-6

Lu D, Minxi H, Zhiying X, Xiaoping S, Haitao W (2017) Frequency domain response analysis of floating wind turbine considering aerodynamic damping. J Hunan Univ 44(1):1-8

Luan C, Michailides C, Gao Z, Moan T (2014) Modeling and analysis of a 5 MW semi-submersible wind turbine combined with three flaptype wave energy converters. Proceedings of the ASME 2014 33rd International Conference on Ocean, Offshore and Arctic Engineering, V09BT09A028-V009BT009A028

Lunde K-OG (2013) Hydrodynamic analysis and structural design of the Concrete Star Wind Floater (Master's thesis, NTNU)

Ma Y, Hu Z-q, L-f X (2014) Wind-wave induced dynamic response analysis for motions and mooring loads of a spar-type offshore floating wind turbine. J Hydrodyn 26(6):865-874

Ma Y, Hu Z-q, L-f X (2015) Wind-wave induced dynamic response analysis for motions and mooring loads of a spar-type offshore floating wind turbine. Journal of Hydrodynamics, Ser B 26(6): $865-874$

Make M (2014) Predicting scale effects on floating offshore wind turbines. MSc Thesis, Confidential

Maniar HD, Newman JN (1997) Wave diffraction by a long array of cylinders. J Fluid Mech 339:309-330

Martin HR (2011) Development of a scale model wind turbine for testing of offshore floating wind turbine systems (Doctoral dissertation, Maine Maritime Academy)

Martin HR, Kimball RW, Viselli AM, Goupee AJ (2014) Methodology for wind/wave basin testing of floating offshore wind turbines. J Offshore Mech Arct Eng 136(2):020905-020903

Masciola M, Robertson A, Jonkman J, Coulling A, Goupee A (2013) Assessment of the importance of mooring dynamics on the global response of the DeepCwind floating semisubmersible offshore wind turbine. Proceedings of the The Twenty-third International Offshore and Polar Engineering Conference

Matha D, Schlipf M, Cordle A, Pereira R, Jonkman J (2011) Challenges in simulation of aerodynamics, hydrodynamics, and mooring-line dynamics of floating offshore wind turbines. National Renewable Energy Laboratory (NREL), Golden, CO

Matha D, Sandner F, Molins C, Campos A, Cheng PW (2015) Efficient preliminary floating offshore wind turbine design and testing methodologies and application to a concrete spar design. Phil Trans R Soc A 373(2035):20140350

Matsukuma H, Utsunomiya T (2008) Motion analysis of a floating offshore wind turbine considering rotor-rotation. IES J Part A Civil Struc Eng 1(4):268-279

Michailides C, Gao Z, Moan T (2016) Experimental and numerical study of the response of the offshore combined wind/wave energy concept SFC in extreme environmental conditions. Mar Struct 50:35-54

Michailides C, Luan C, Gao Z, Moan T (2014) Effect of flap type wave energy converters on the response of a semi-submersible wind turbine in operational conditions. Proceedings of the ASME 2014 33rd International Conference on Ocean, Offshore and Arctic Engineering, V09BT09A014-V009BT009A014

Molins C, Rebollo J, Campos A (2011) Estructura flotante de hormigón prefabricado para soporte de aerogenerador Patent No WO201393160

Molins i Borrell C, Campos Hortigüela A, Sandner F, Matha D (2014) Monolithic concrete off-shore floating sturcture for wind turbines.
Proceedings of the EWEA 2014 Annual Event: conference proceedings, 107-111

Morison JR, Johnson JW, Schaaf SA (1950) The force exerted by surface waves on piles. J Pet Technol 2(5):149-154

Müller K, Sandner F, Bredmose H, Azcona J, Manjock A, Pereira R (2014) Improved tank test procedures for scaled floating offshore wind turbines. Proceedings of the IWEC 2014.

Munteanu I, Bratcu AI, Bacha S, Roye D, Guiraud J (2010) Hardware-inthe-loop-based simulator for a class of variable-speed wind energy conversion systems: design and performance assessment. IEEE Transac Energy Conver 25(2):564-576

Murai M, Nishimura R (2010) A study on an experiment of behavior of a SPAR type offshore wind turbine considering rotation of wind turbine blades. Proceedings of the OCEANS 2010 IEEE-Sydney, 1-8

Musial W, Butterfield S, Boone A (2003) Feasibility of floating platform systems for wind turbines: preprint. The 23rd ASME Wind Energy, Reno

Myhr A, Maus KJ, Nygaard TA (2011) Experimental and computational comparisons of the OC3-Hywind and tension-leg-buoy (TLB) floating wind turbine conceptual designs. Proceedings of the The Twenty-first International Offshore and Polar Engineering Conference

Naciri M, Waals O, de Wilde J (2007) Time domain simulations of sideby-side moored vessels: lessons learnt from a benchmark test. Proceedings of the ASME 2007 26th International Conference on Offshore Mechanics and Arctic Engineering, 801-811

Naciri M, Buchner B, Bunnik T, Huijsmans R, Andrews J (2004) Low frequency motions of LNG carriers moored in shallow water. Proceedings of the ASME 2004 23rd International Conference on Offshore Mechanics and Arctic Engineering, 995-1006

Nakashima M, Kato H, Takaoka E (1992) Development of real-time pseudo dynamic testing. Earthquake Engng. Struct Dyn 21(1)

Namik H, Stol K (2010) Individual blade pitch control of floating offshore wind turbines. Wind energy 13(1):74-85

Namik H, Stol K (2011) Performance analysis of individual blade pitch control of offshore wind turbines on two floating platforms. Mechatronics 21(4):691-703

Namik H, Stol K (2013) A review of floating wind turbine controllers. In: Handbook of Wind Power Systems, pp 415-441

Nematbakhsh A, Bachynski EE, Gao Z, Moan T (2015) Comparison of wave load effects on a TLP wind turbine by using computational fluid dynamics and potential flow theory approaches. Appl Ocean Res 53:142-154

Newton JM, Cameron MP, Urbina R, Kimball RW, Goupee AJ, Thiagarajan KP (2015) Characterization of a wind tunnel for use in offshore wind turbine development. Proceedings of the ASME 2015 34th International Conference on Ocean, Offshore and Arctic Engineering, V009T009A048-V009T009A048

Ng C, Ran L (2016) Offshore wind farms: technologies, design and operation. Vol. number 92. Cambridge: Elsevier Science \& Technology

Nielsen FG, Hanson TD, Skaare Br (2006) Integrated dynamic analysis of floating offshore wind turbines. Proceedings of the 25 th International Conference on Offshore Mechanics and Arctic Engineering, 671-679

Ogilvie TF (1964) Recent progress toward the understanding and prediction of ship motions. Proceedings of the 5th ONR Symp. on Naval Hydrodynamics

Oh Y, Kim K, Kim H, Paek I (2015) Control algorithm of a floating wind turbine for reduction of tower loads and power fluctuation. Int $\mathrm{J}$ Precis Eng Manuf 16(9):2041-2048

Ohkawa Y, Yago K, Ohta M, Yamada Y, Takano O, Sekita K (2004) A basic study of floating wind power system for purpose of alternative fuel production. Proceedings of the Proceedings of Civil Engineering in the Ocean, 1217-1222 
Ormberg H, Bachynski EE (2012) Global analysis of floating wind turbines: code development, model sensitivity and benchmark study. Proceedings of the Twenty-second International Offshore and Polar Engineering Conference

Øye S (1996) FLEX4 simulation of wind turbine dynamics. Proceedings of the Proceedings of the 28th IEA Meeting of Experts Concerning State of the Art of Aeroelastic Codes for Wind Turbine Calculations (Available through International Energy Agency)

Pao LY, Johnson KE (2011) Control of wind turbines. IEEE Control Syst 31(2):44-62

Pardalos PM, Rebennack S, Pereira MVF, Iliadis NA, Pappu V (2013) Handbook of wind power systems. Springer, Berlin

Pegalajar-Jurado A, Hansen AM, Laugesen R, Mikkelsen RF, Borg M, Kim T, Heilskov NF, Bredmose H (2016) Experimental and numerical study of a 10MW TLP wind turbine in waves and wind. Proceedings of the Journal of Physics: Conference Series, 092007

Philippe M, Babarit A, Ferrant P (2014) Aero-hydro-elastic simulation of a semi-submersible floating wind turbine. J Offshore Mech Arct Eng 136(2):020908

Philippe M, Courbois A, Babarit A, Bonnefoy F, Rousset J-M, Ferrant P (2013) Comparison of simulation and tank test results of a semisubmersible floating wind turbine under wind and wave loads. Proceedings of the ASME 2013 32nd International Conference on Ocean, Offshore and Arctic Engineering, V008T009A081V008T009A081

Pinto AV, Pegon P, Magonette G, Tsionis G (2004) Pseudo-dynamic testing of bridges using non-linear substructuring. Earthq Eng Struct Dyn 33(11):1125-1146

Plummer AR (2006) Model-in-the-loop testing. Proceedings of the Institution of Mechanical Engineers. Part I J Syst Control Eng 220(3): 183-199

Power P (2019). WindFloat, 2019(11/7)

Ramachandran GKVK (2013) A numerical model for a floating TLP wind turbine Technical University of Denmark (DTU)

Ramos R (2012) Actuator saturation control of floating wind turbines. Proceedings of the ASME 2012 31st International Conference on Ocean, Offshore and Arctic Engineering, 359-367

Robertson A, National Renewable Energy L (2014) Definition of the semisubmersible floating system for phase II of OC4 (No. NREL/TP-5000-60601). National Renewable Energy Lab.(NREL), Golden, CO (United States)

Robertson AN, Jonkman JM, Goupee AJ, Coulling AJ, Prowell I, Browning J, Masciola MD, Molta P (2013) Summary of conclusions and recommendations drawn from the DeepCwind scaled floating offshore wind system test campaign. Proceedings of the ASME 2013 32nd International Conference on Ocean, Offshore and Arctic Engineering, V008T009A053-V008T009A053

Robertson AN, Wendt F, Jonkman JM, Popko W, Dagher H, Gueydon S, Qvist J, Vittori F, Azcona J, Uzunoglu E, Soares CG, Harries R, Yde A, Galinos C, Hermans K, de Vaal JB, Bozonnet P, Bouy L, Bayati I, Bergua R, Galvan J, Mendikoa I, Sanchez CB, Shin H, Oh S, Molins C, Debruyne Y (2017) OC5 project phase II: validation of global loads of the DeepCwind floating semisubmersible wind turbine. Energy Procedia 137:38-57

Rockel S, Camp E, Schmidt J, Peinke J, Cal RB, Hölling M (2014) Experimental study on influence of pitch motion on the wake of a floating wind turbine model. Energies 7(4):1954-1985

Roddier D, Cermelli C, Weinstein A (2009) WindFloat: a floating foundation for offshore wind turbines - part I: design basis and qualification process. Proceedings of the ASME 2009 28th International Conference on Ocean, Offshore and Arctic Engineering, 845-853

Roddier D, Cermelli C, Aubault A, Weinstein A (2010) WindFloat: a floating foundation for offshore wind turbines. J Renew Sustain Energy 2(3):033104

Salehyar S, Zhu Q (2015) Aerodynamic dissipation effects on the rotating blades of floating wind turbines. Renew Energy 78:119-127
Sandner F, Amann F, Azcona J, Munduate X, Bottasso CL, Campagnolo F, Robertson A (2015) Model building and scaled testing of 5MW and 10MW semi-submersible floating wind turbines. Proceedings of the Proceedings of 12th Deep Sea Offshore Wind R\&D Conference, EERA DeepWind'2015

Sant T, Cuschieri K (2015) Numerical modelling of the aerodynamic characteristics of a floating offshore wind turbine under yawed rotor conditions. Proceedings of the ASME 2015 34th International Conference on Ocean, Offshore and Arctic Engineering, V009T009A046-V009T009A046

Sarpkaya T, Isaacson M (1981) Mechanics of wave forces on offshore structures. J Appl Mech 49(2):466-467

Sauder T, Chabaud V, Thys M, Bachynski EE, Sæther LO (2016) Realtime hybrid model testing of a braceless semi-submersible wind turbine: part I - the hybrid approach, (49972), V006T009A039

Savenije F, Peeringa J (2014) Control development for floating wind. Proceedings of the Journal of Physics: Conference Series, 012090

Schlipf D, Sandner F, Raach S, Matha D, Cheng PW (2013) Nonlinear model predictive control of floating wind turbines

Sclavounos P (2008) Floating offshore wind turbines. Mar Technol Soc J 42(2):39-43

Sebastian T, Lackner M (2012) Analysis of the induction and wake evolution of an offshore floating wind turbine. Energies 5(4):968-1000

Sebastian T, Lackner MA (2013) Characterization of the unsteady aerodynamics of offshore floating wind turbines. Wind Energy 16(3): 339-352

Serraris JJ (2009) Time domain analysis for DP simulations. Proceedings of the ASME 2009 28th International Conference on Ocean, Offshore and Arctic Engineering, 595-605

Sethuraman L, Venugopal V (2013) Hydrodynamic response of a stepped-spar floating wind turbine: numerical modelling and tank testing. Renew Energy 52:160-174

Shao X, Griffith C (2013) An overview of hybrid simulation implementations in NEES projects. Eng Struct 56:1439-1451

Shi R (2015) Research on optimal design and fatigue characteristics of support structure for deep water TLP floating wind turbine. China Ocean University

Shin H (2011) Model test of the OC3-Hywind floating offshore wind turbine. The Twenty-first International Offshore and Polar Engineering Conference

Signorelli C, Villegas C, Ringwood J (2011) Hardware-in-the-loop simulation of a heaving wave energy converter. Proceedings of the Proceedings of the 9th European Wave and Tidal Energy Conference (EWTEC)

Skaare B, David Hanson T, Nielsen F, Yttervik R, Melchior Hansen A, Thomsen K, Larsen T (2007) Integrated dynamic analysis of floating offshore wind turbines. In European wind energy conference and exhibition (pp. 7-10). Hamburg, Germany

Stewart G, Muskulus M (2016a) A review and comparison of floating offshore wind turbine model experiments. Energy Procedia 94:227231

Stewart G, Muskulus M (2016b) Aerodynamic simulation of the MARINTEK Braceless semisubmersible wave tank tests. Proceedings of the Journal of Physics: Conference Series, 012012

Stewart G, Lackner M, Robertson A, Jonkman J, Goupee A (2012) Calibration and validation of a FAST floating wind turbine model of the DeepCwind scaled tension-leg platform: preprint. National Renewable Energy Laboratory (NREL), Golden, CO.

Stiesdal H (2009) Hywind: the world's first floating MW-scale wind turbine. Wind Directions 31:52-53

Sukegawa H, Ishihara T, Yamaguchi A, Fukumoto Y, Tuchiya M (2006) A study of floating offshore wind turbine systems part I: an offshore wind observation and wind energy potential assessment. Proceedings of the Proceedings of the 28th wind energy utilization symposium, Tokyo, Japan, 196-199 
Suzuki H, Hashimoto T, Sekita K (2004) Improvement of response characteristics of SPAR-buoy type floating wind turbine. Proceedings of the Proceedings of Civil Engineering in The Ocean, 911-916

Tang Y, Wang H, Tao H, Liu Z (2013) Design of semi-submersible floating foundation structure and overall strength analysis of offshore wind turbine. China Shipbuilding 54(3):85-93

Tang Y, Gui L, Cao Y, Qin Y (2014) Semi-submersible foundation concept design and hydrodynamic performance analysis of offshore wind turbine. J Harbin Eng Univ 35(11):1314-1319

Thiagarajan KP, Dagher HJ (2014) A review of floating platform concepts for offshore wind energy generation. J Offshore Mech Arct Eng 136(2):020903

Tran T, Kim D, Song J (2014) Computational fluid dynamic analysis of a floating offshore wind turbine experiencing platform pitching motion. Energies 7(8):5011-5026

Tsujimoto S, Dessort S, Hara N, Konishi K (2014) Pitch angle control of floating offshore wind turbines by $\mathrm{H}^{\infty}$ control. IEEJ Transact Electron Inform Syst 134:1096-1103

Utsunomiya T, Nishida E, Sato I (2009a) Wave response experiment on SPAR-type floating bodies for offshore wind turbine. Proceedings of the The Nineteenth International Offshore and Polar Engineering Conference

Utsunomiya T, Sato T, Matsukuma H, Yago K (2009b) Experimental validation for motion of a SPAR-type floating offshore wind turbine using 1/22.5 scale model(43444), 951-959

Utsunomiya T, Sato I, Yoshida S, Ookubo H, Ishida S (2013a) Dynamic response analysis of a floating offshore wind turbine during severe typhoon event. Proceedings of the ASME 2013 32nd International Conference on Ocean, Offshore and Arctic Engineering, V008T009A032-V008T009A032

Utsunomiya T, Yoshida S, Ookubo H, Sato I, Ishida S (2014) Dynamic analysis of a floating offshore wind turbine under extreme environmental conditions. J Offshore Mech Arct Eng 136(2):020904

Utsunomiya T, Matsukuma H, Minoura S, Ko K, Hamamura H, Kobayashi O, Sato I, Nomoto Y, Yasui K (2013b) At sea experiment of a hybrid spar for floating offshore wind turbine using 1/10 scale model. J Offshore Mech Arct Eng 135(3):034503

van Essen S, van der Hout A, Huijsmans R, Waals O (2013) Evaluation of directional analysis methods for low-frequency waves to predict LNGC motion response in nearshore areas. Proceedings of the ASME 2013 32nd International Conference on Ocean, Offshore and Arctic Engineering, V001T001A015-V001T001A015

Van Phuc P, Ishihara T (2007) A study on the dynamic response of a semi-submersible floating offshore wind turbine system part 2: numerical simulation. ICWE12. Cairns, Australia, 959-966

Viselli AM, Goupee AJ, Dagher HJ (2015) Model test of a 1: 8-scale floating wind turbine offshore in the gulf of Maine. J Offshore Mech Arct Eng 137(4):041901

Vita L, Ramachandran GKV, Krieger A, Kvittem MI, Merino D, CrossWhiter J, Ackers BB (2015) Comparison of numerical models and verification against experimental data, using Pelastar TLP concept. Proceedings of the ASME 2015 34th International Conference on Ocean, Offshore and Arctic Engineering, V009T009A047V009T009A047

Vittori F, Bouchotrouch F, Lemmer F, Azcona. J (2018) Hybrid scale testing of a $5 \mathrm{MW}$ floating wind turbine using the SIL method compared with numerical models. Proceedings of the Ocean, Offshore and Arctic Engineering OMAE

Wan L, Gao Z, Moan T (2015) Experimental and numerical study of hydrodynamic responses of a combined wind and wave energy converter concept in survival modes. Coast Eng 104:151-169

Wan L, Gao Z, Moan T, Lugni C (2016a) Experimental and numerical comparisons of hydrodynamic responses for a combined wind and wave energy converter concept under operational conditions. Renew Energy 93:87-100

Wan L, Gao Z, Moan T, Lugni C (2016b) Comparative experimental study of the survivability of a combined wind and wave energy converter in two testing facilities. Ocean Eng 111:82-94

Wan L, Greco M, Lugni C, Gao Z, Moan T (2017) A combined wind and wave energy-converter concept in survival mode: numerical and experimental study in regular waves with a focus on water entry and exit. Appl Ocean Res 63:200-216

Wang K, Ji C, Xue H, Tang W (2017) Frequency domain approach for the coupled analysis of floating wind turbine system. Ships Offshore Struct 12(6):767-774

Wang L, Zuo S, Song YD, Zhou Z (2014) Variable torque control of offshore wind turbine on spar floating platform using advanced RBF neural network. Proceedings of the Abstract and Applied Analysis,

Wayman EN, Sclavounos PD, Butterfield S, Jonkman J, Musial W (2006) Coupled Dynamic Modeling of Floating Wind Turbine Systems: Preprint. National Renewable Energy Lab.(NREL), Golden, $\mathrm{CO}$ (United States)

Wehmeyer C, Ferri F, Frigaard PB, Skourup J (2013) Experimental study of an offshore wind turbine TLP in ULS conditions. Proceedings of the The Twenty-third International Offshore and Polar Engineering Conference

Wei K, Arwade SR, Myers AT (2014) Incremental wind-wave analysis of the structural capacity of offshore wind turbine support structures under extreme loading. Eng Struct 79:58-69

Wilson RE, Walker SN, Heh P (1999) Technical and user's manual for the FAST_AD advanced dynamics code. OSU/NREL Report(9901)

Windsea AS (2010) Next generation floating wind farm. Scand Oil-Gas Mag 7(8):250-253

Withee JE (2004) Fully coupled dynamic analysis of a floating wind turbine system. Massachusetts Inst of Tech, Cambridge

Wu J, Ding JH, He YP, Zhao YS (2015) Study on unsteady aerodynamic performance of floating offshore wind turbine by CFD method. Proceedings of the Twenty-fifth International Ocean and Polar Engineering Conference

Yago K, Ohkawa Y, Miyajima S, Chujo T, Ishii K, Takano O (2007) Comprehensive evaluations on feasibility of floating wind power system. Proceedings of the Proceedings of Civil Engineering In The Ocean, 1009-1014

Yu W, Lemmer F, Bredmose H, Borg M, Pegalajar-Jurado A, Mikkelsen RF, Larsen TS, Fjelstrup T, Lomholt AK, Boehm L, Schlipf D, Armendariz JA, Cheng PW (2017) The triple spar campaign: implementation and test of a blade pitch controller on a scaled floating wind turbine model. Energy Procedia 137:323-338

Zambrano T, MacCready T, Kiceniuk T, Roddier DG, Cermelli CA (2006) Dynamic modeling of Deepwater offshore wind turbine structures in Gulf of Mexico storm conditions. In: Proceedings of the 25th international conference on offshore mechanics and Arctic engineering, pp 629-634

Zhang L, Deng H (2011) Numerical analysis of stability of floating wind turbine semi-submersible platform. Applied Technol 38(10):13-17

Zhang L, Ye X, Wu H, Ma Q (2013) Analysis of environmental load and motion performance of offshore floating wind turbine. J Sol Energy 34(5):876-881

Zhao J, Zhang L, Wu H (2012) Motion performance and mooring system of a floating offshore wind turbine. J Mar Sci Appl 11(3):328-334

Zhao W, Wan D (2014) Wind turbine impacts on its semi-submersible floating supporting system for phase II of OC4. Proceedings of the The Twenty-fourth International Ocean and Polar Engineering Conference

Zhou K, Doyle JC (1998) Essentials of robust control. Prentice hall, Upper Saddle River, NJ 